\title{
Projected near-term changes in three types of heat waves over China under RCP4.5
}

Article

Accepted Version

Su, Q. and Dong, B. (2019) Projected near-term changes in three types of heat waves over China under RCP4.5. Climate Dynamics, 53 (7-8). pp. 3751-3769. ISSN 0930-7575 doi: https://doi.org/10.1007/s00382-019-04743-y Available at https://centaur.reading.ac.uk/83090/

It is advisable to refer to the publisher's version if you intend to cite from the work. See Guidance on citing.

Published version at: https://link.springer.com/article/10.1007/s00382-019-04743-y

To link to this article DOI: http://dx.doi.org/10.1007/s00382-019-04743-y

Publisher: Springer

All outputs in CentAUR are protected by Intellectual Property Rights law, including copyright law. Copyright and IPR is retained by the creators or other copyright holders. Terms and conditions for use of this material are defined in the End User Agreement.

www.reading.ac.uk/centaur

\section{CentAUR}


Central Archive at the University of Reading

Reading's research outputs online 
1

2

3

4

5

6

7

8

9

10

11

12

13

14

15

16

17

18

19

20

21

22

23

24

25

26

27

\section{under RCP4.5}

Su Qin ${ }^{1}$ and Buwen Dong ${ }^{2}$

${ }^{1}$ Department of Atmospheric Sciences, Yunnan University, Kunming, China

${ }^{2}$ National Centre for Atmospheric Science-Climate, Department of Meteorology, University of Reading, Reading, UK

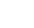

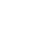

(1)

2

13

1 Corresponding author:

Qin $\mathrm{Su}$,

3 Department of Atmospheric Sciences,

4 Yunnan University,

25 Kunming, 650091, China

6 E-mail: suqin@ynu.edu.cn 


\section{Abstract}

The future changes in three aspects of frequency, intensity, and duration of the compound, daytime, and nighttime heat waves (HWs) over China during extended summer (May-September) in a future period of the mid-2 $1^{\text {st }}$ century (FP; 2045-2055) under RCP4.5 scenario relative to present day (PD; 1994-2011) are investigated by two models, i.e. MetUM-GOML1 and MetUM-GOML2, comprising the atmospheric components of two state-of-the-art climate models coupled to a multi-level mixed-layer ocean model. The results show that all three types of HWs over China will occur more frequently with strengthened intensity and elongated duration in the mid- $21^{\text {st }}$ century. The compound HWs will change most dramatically with the frequency in the FP being 4-5 times that in the PD, and the intensity and duration doubling those in the PD. The changes of daytime and nighttime HWs are also remarkable, with the changes of nighttime HWs larger than those of daytime HWs. The future changes of the three types of HWs over China in two models are similar in terms of spatial patterns and area averaged quantities, indicating these projected changes of HWs over the China under RCP4.5 scenario are robust. The further analyses suggest that projected future changes of HWs over China are predominantly determined by the increase in seasonal mean surface air temperatures with change in temperature variability playing a minor role. The seasonal mean temperature increases are partly due to the increase in surface downward longwave radiation and partly due to the increase in surface shortwave radiation. The increased downward longwave radiation results from the enhanced greenhouse effect and the increased water vapor in the atmosphere. The increased 
surface shortwave radiation results from the decreased aerosol emissions via direct aerosol-radiation interaction and indirect aerosol-cloud interaction over southeastern and northeastern China and the decreased cloud cover related to reduced relative humidity.

Key words: heat waves, heat wave types, future changes, China, coupled models.

\section{Introduction}

Heat waves are usually defined as abnormally hot weather lasting for several days (Perkins and Alexander 2013; Perkins 2015). This distinct type of extreme temperature events has caused substantial damages to socioeconomics and human health (e.g. Robine et al. 2008; Coumou and Rahmstorf 2012; Hatfield and Prueger 2015; Lesk et al. 2016). In recent two decades, heat waves have occurred more frequently all over the world (e.g., Meehl and Tebaldi 2004; Seneviratne et al. 2014). Without any exception, several severe heat waves hit China recently in different regions and broke the regional historical temperature records, such as the 2013 July-August heat wave in the lower reaches of Yangtze River Valley (Sun et al. 2014; Zhou et al. 2014b; Ma et al. 2017), the 2015 summer heat wave in western China (Sun et al. 2016), and the 2017 July heat wave in central eastern China (Chen et al. 2018; Sparrow et al. 2018). These catastrophic events led to enormous economic loss and heat-related morbidity and mortality in China (e.g., Tan et al. 2007; Sun et al. 2016; Ma et al. 2017). The increased occurrence of heat waves largely results from the increased mean temperature (Argueso et al. 2016; Su and Dong 2019). As the increase in mean temperature will go on, how 
the heat waves will change in the future under the global warming scenario is an important issue for developing climate adaptation strategies.

of occurrence, the heat waves are related to different mechanisms and of different impacts (Gershunov et al. 2009, Freychet et al. 2017). The heat waves in the day, usually associated with dry conditions (Black et al. 2004; Gershunov et al. 2009; Wang et al. 2016), have a variety of disastrous impacts on infrastructures, ecosystem, and human life (Wilbanks et al. 2012), while the heat waves at night, related to wet conditions (Gershunov et al. 2009; Chen and Lu 2014), have relatively weak impact. However, with the hot nights enhancing the damages of daytime high temperatures on human health (Gosling et al 2009), the heat waves persisting throughout the day and night are the most disastrous among these three types of heat waves (Karl and Knight 1997). Thus, recent studies applied a more precise classification of heat waves according to the timing of their occurrence to get more insights, which divided the heat waves into three types, i.e., daytime, nighttime and compound ones (e.g., Chen and Li 2017; Chen and Zhai 2017; Freychet et al. 2017; Su and Dong 2019).

In recent decades since the mid-20th century, the previously-defined heat waves, which only consider the daytime temperatures and involve the daytime heat waves and part of the compound heat waves, show increasing frequency and duration over China (Li et al. 2017; Luo and Lau 2017; Wang et al. 2017; You et al. 2017). Some recent studies, using the precisely defined daytime, nighttime, and compound heat waves over 
most part of China, show significant increasing trends in frequency, intensity, and duration (Chen and Zhai 2017; Freychet et al. 2017). Particularly, the increase of frequency and intensity in compound and nighttime heat waves is much greater than that in daytime ones (Chen and Li 2017; Chen and Zhai 2017; Su and Dong 2019). The anthropogenic influences are highlighted to play crucial roles in the sharp increase in occurrence of the heat waves over China (e.g., Wilcox et al. 2015; Freychet et al. 2018). In more detail, Su and Dong (2019) reported that the increase in greenhouse gas concentration is responsible for the decadal increase in frequency, intensity, and spatial extent of the three types of heat waves over China across mid-1990s and the changes in anthropogenic aerosol emission lead to the increase in frequency and intensity of the daytime heat waves over Northeastern China and decrease the frequency and intensity of daytime HWs over Southeastern China.

Considering the anthropogenic influences, future changes in the heat waves and temperature extremes over China are assessed under different scenarios. There would be an increase in warm extremes and a decrease in cold extremes under a warming climate (Zhou et al. 2014a; Yu et al. 2018). The frequency and duration of previouslydefined heat waves over China would increase and the increase would become larger when the mean temperature gets greater (Guo et al. 2017). However, only the future changes in previously-defined heat waves are estimated and the assessment of future changes in precisely defined compound, daytime, and nighttime heat waves is still lacking. Meanwhile all above projections have used fully coupled general circulation models (CGCMs). However, these CGCMs exhibit significant biases in simulated sea 
surface temperature that challenge the reliability of climate projections (Wang et al. 2014).

Therefore, the main aims of this work are to estimate the future changes of the daytime, nighttime, and compound heat waves over China and to reveal the associated physical processes by using two near-globally coupled models comprising the atmospheric components of two state-of-the-art climate models coupled to a multi-level mixed-layer ocean and having a much smaller bias in simulated sea surface temperature (Hirons et al. 2015, Dong et al. 2017, Luo et al. 2018). The structure of this paper is organized as follows: The model and experiments are described in Section 2. Model simulated extended seasonal mean surface air temperatures and definition of HWs are described in Section 3. The projected changes in the three types of heat waves are shown in Section 4. The physical processes responsible for future changes in heat waves are illustrated in Section 5. Conclusions are summarized in Section 6.

\section{Models and experiments}

\subsection{Models}

Two coupled models, MetUM-GOML1 and MetUM-GOML2 (Hirons et al. 2015), that comprise the atmospheric components of two state-of-the-art climate models coupled to a multi-level mixed-layer ocean model, are used in this study. The atmospheric component for MetUM-GOML1 is the Met Office Unified Model (MetUM) at the fixed scientific configuration Global Atmosphere 3.0 (GA3.0; Arribas et al. 2011; Walters et al. 2011). The atmospheric component for MetUM-GOML2 is 
the MetUM GA6.0. The largest change in GA6.0 is that the "New Dynamics" dynamical core is replaced with "ENDGame" (Walters et al. 2014). ENDGame maintains the benefits of "New Dynamics", whilst improving its accuracy, stability and scalability. The improved accuracy significantly reduces the model's implicit damping, leading to a beneficial improvement to various modes of variability, such as the vertical height of extra-tropical cyclones and the structure of frontal systems. The details about GA6.0 are described in Walters et al. 2017. The resolution for these two atmospheric models is $1.875^{\circ}$ longitude by $1.25^{\circ}$ latitude with 85 vertical layers. The models include an interactive tropospheric aerosol scheme, which is able to simulate the direct, indirect and semi-direct effects of aerosols (Walters et al. 2011; Jones et al. 2011). The oceanic components for MetUM-GOML1 and MetUM-GOML2 are the same, which is a MultiColumn K Profile Parameterization (MC-KPP) mixed-layer ocean model. The horizontal resolution of MC-KPP is the same as the MetUM where it is coupled. The vertical resolution of MC-KPP is very high at the surface $(1.2 \mathrm{~m})$ and near the surface ( $2 \mathrm{~m}$ over the first $41.5 \mathrm{~m}$ ), since the MC-KPP columns with 100 levels over a depth of $1000 \mathrm{~m}$ are defined using a stretch function. MC-KPP simulates only vertical mixing and does not include ocean dynamics, so the corrections for temperature and salinity based on the seasonally-varying 3-dimension temperature and salinity flux are prescribed to represent the mean ocean advection and account for biases in atmospheric surface heat and fresh water fluxes. The atmospheric and oceanic components are coupled every three hours. The air-sea coupling is limited by the maximum extent of a seasonally varying sea ice climatology (Hirons et al. 2015). These models are 
computationally cheaper than models with a fully interactive ocean. More important, they have a smaller bias in simulated sea surface temperature (Hirons et al., 2015, Dong et al. 2017; Luo et al. 2018) in comparison with fully coupled models (e.g., Wang et al. 2014) whilst also retaining intra-seasonal variability and coupling between the atmosphere and the ocean.

\subsection{Experiments}

The experiments performed in this study are summarized in Table 1. A 12-year relaxation experiment (R0) for both MetUM-GOML1 and MetUM-GOML2 models was firstly performed in which the MC-KPP profiles of temperature and salinity were relaxed to a present day (PD, 1994-2011) ocean temperature and salinity climatology derived from the Met Office ocean analysis (Smith and Murphy 2007). The relaxation experiment used PD anthropogenic greenhouse gas (GHG) and anthropogenic aerosol (AA) forcings (Lamarque et al. 2010; 2011). The daily mean seasonal cycle of ocean temperature and salinity corrections from the coupled relaxation experiment are then imposed in free-running coupled experiments. Three other time-sliced experiments using both models are performed by using different forcings, i.e. C-EP experiment forced by the early period (EP, 1964-1981) mean GHG concentrations and AA emissions, C-PD experiment forced by the PD (1994-2011) mean GHG concentrations and AA emissions, C-FP experiment forced by future period (FP, 2045-2055) mean GHG concentrations and AA emissions under the scenario of representative concentration pathway (RCP) 4.5. The single RCP4.5 scenario is chosen for 
178

179

projection because the radiative forcings in the four scenarios of RCP2.6, RCP4.5, RCP6.0, and RCP8.5 do not differ significantly in the FP of the mid- $21^{\text {st }}$ century (Moss et al., 2010). Relative to PD means, FP mean GHG concentrations increase $\left(\mathrm{CO}_{2}\right.$ by $30 \%, \mathrm{CH}_{4}$ by $4.5 \%$, and $\mathrm{N}_{2} \mathrm{O}$ by $10.4 \%$ ) and the emission of sulfur dioxide, which is one of the most important aerosol species, decreases over the Europe (by $74 \%$ ), the East Asia (by 79\%), and the North America (by 81\%) but increases over Indian subcontinent (Fig. 1). All experiments are run for 50 years and use the climatological PD sea ice extent from the Met Office Hadley Center Sea Ice and Sea Surface Temperature data set (HadISST; Rayner et al. 2003). The last 45 years of each experiment are used for analysis.

\section{Model simulated extended summer seasonal mean surface air temperatures} and HWs

\subsection{Model performance in simulating early period surface air temperatures}

The climatological means of daily maximum temperature (Tmax) and daily minimum temperature (Tmin) in the C-EP experiments of MetUM-GOML1 and MetUM-GOML2 for the extended summer are compared with the observed ones during EP (Fig. 2). The observational data used is the homogenized datasets of daily Tmax and Tmin series at 753 stations in China ( $\mathrm{Li}$ et al. 2016). The observed Tmax pattern shows more or less uniform distributions over southeastern China with value higher than $28^{\circ} \mathrm{C}$ and apparent meridional gradient over northeastern China. Over western China, a low value centre locates over the Tibetan Plateau and a high value centre is over 
northwestern China with temperature above $28{ }^{\circ} \mathrm{C}$ (Fig. 2a). The observed climatological Tmin exhibits great meridional gradient over eastern China with the maximum higher than $22{ }^{\circ} \mathrm{C}$ in the southeast coast of China and minimum of $4-7^{\circ} \mathrm{C}$ over northeastern China. The spatial distribution of Tmin over western China shows a minimum (less than $1{ }^{\circ} \mathrm{C}$ ) over the Tibetan Plateau and a high value (more than $16{ }^{\circ} \mathrm{C}$ ) over northwestern China, being similar to the spatial pattern in Tmax (Fig. 2b). The spatial patterns of climatological extended summer means of Tmax and Tmin and regional magnitudes in the C-EP experiments of MetUM-GOML1 and MetUMGOML2 agree well with the observed ones with pattern correlation coefficients of 0.85 and 0.86 for Tmax and 0.90 and 0.91 for Tmin (Fig. 2c-f). The two models reproduce the observed Tmax distributions over the southeastern and northwestern part of China with value above $28{ }^{\circ} \mathrm{C}$, but slightly underestimate Tmax over the Tibetan Plateau and northeastern China (Fig. 2c and e). The observed Tmin distributions are also well simulated by the model, with some underestimation over the Tibetan Plateau (Fig. 2d).

\subsection{HWs definition}

Three types of HWs, namely compound, daytime, and nighttime HWs, are defined in this study in the same way as the former study on decadal changes across the mid1990s over China (Su and Dong 2019). Considering the various climate types in China, the relative threshold, which is determined by local climate and varies at different places on different dates (Stefanon et al. 2012), is employed to define the heat waves over China in this study, as was used in some previous studies (e.g., Li et al. 2017; Chen and 
Li 2017; Wang et al. 2017). The relative threshold on each model calendar day is calculated as the daily 90th percentile of daily Tmax or Tmin based on 15-day samples centered on that day during the last 45 years of C-EP experiment (i.e. total samples $15 * 45=675$ days, Della-Marta et al. 2007). A compound HW, continuous hot weather in day and night, is defined when both Tmax and Tmin are higher than the thresholds for at least three days. A daytime (nighttime) HW, continuous hot weather only in the day (at night), is defined when only Tmax (Tmin) exceeds the thresholds for at least three days. All these three types of HWs are independent of each other.

Three indicators, i.e. frequency, intensity, and duration, are used to measure the HWs in a year. The frequency is represented by the accumulated occurrence of events within a year. The intensity of each event is calculated by averaging the everyday temperature exceedance above the threshold within an event. Particularly, the intensity of compound HWs is the sum of the averaged Tmax and Tmin exceedances. The duration of each event is the number of days when an event endures. The intensity and duration for a year is computed by averaging the intensity and duration of events occurring in that year.

\subsection{Model performance in simulating early period HWs}

The frequency, intensity, and duration of compound, daytime, and nighttime HWs in the C-EP experiment of MetUM-GOML1 and MetUM-GOML2 during the extended summer are compared with those in observations in the EP (Fig. S1-3). In observations, the frequency, intensity, and duration of compound HWs share similar spatial patterns, 
with relatively large values over the southeastern China and the northern margin of mainland China (Fig. S1a-c). The daytime HWs in the EP are of the largest frequency and duration over the western China and of the greatest intensity over the northern margin of mainland China (Fig. S2a-c). The frequency and duration of nighttime HWs are relatively high over the central China and the intensity of nighttime HWs are the greatest over the northern margin of mainland China (Fig. S3a-c). The spatial patterns of the frequency, intensity, and duration of all three types of HWs in observations are well reproduced by these two models, despite the underestimation of the frequency and duration of daytime HWs over the western China. The biases of the area averaged indices are examined by using the relative bias, which is defined as the absolute bias (model simulated index minus observational one) divided by observational index. The relative biases for various regions range from $-12 \%$ to $-43 \%$ in MetUM-GOML1 and $2 \%$ to $-55 \%$ in MetUM-GOML2. According to Guo et al. (2017), which used 12 CMIP5 models to project the previously-defined HWs, the absolute value of the smallest relative bias of the previously-defined HWs in all 12 CMIP5 models is $36.66 \%$. Comparing to their smallest relative bias, the smallest relative bias in MetUM-GOML1 and MetUM-GOML2 is much smaller, indicating a better ability of MetUM-GOML1 and MetUM-GOML2 in simulating the observed HWs. All the results above indicate these two models' capability of capturing the characteristics of the HWs in observations over China.

The good agreements in extended summer seasonal mean surface Tmax and Tmin between model simulations and observations in many aspects and the models' ability 
of capturing the characteristics of the HWs over China suggest a fidelity of using these models for projecting their future changes. In addition, C-EP and C-PD experiments were used to investigate the decadal changes in the East Asian summer monsoon, temperature extremes over China, and HWs over China across the mid-1990s (Chen and Dong 2018; Su and Dong 2019; Tian et al. 2018). It is indicated by the previous studies that the circulation and precipitation over East Asia in present day and their decadal changes across the mid-1990s simulated by these two models are consistent with those in observations.

Previous studies on the HWs over China demonstrated significant observed decadal changes in frequency, intensity, and spatial pattern of the compound, daytime, and nighttime HWs over China across the mid-1990s (Chen and Li 2017; Chen and Zhai 2017; Su and Dong 2019). Su and Dong (2019) quantified that the frequency of compound HWs averaged over China in the PD almost triples that in the EP while both intensity and spatial extent are nearly doubled. In addition, their analyses also indicated that the changes of daytime and nighttime HWs are also significant in all three aspects, though not as dramatical as changes of the compound HWs. They further attributed the observed decadal changes to the changes in anthropogenic forcings. In order to compare the projected future changes in context of model simulated past decadal-multidecadal changes, the relative thresholds for three types of HWs in this study are based on early period C-EP simulations as described in above and used in Su and Dong (2019). The future changes of the HWs over China are indicated by the differences between C-FP and C-PD experiments. Statistical significance of the mean changes is assessed using a 
two tailed Student's t-test.

286

287

288

289

290

291

292

293

294

295

296

297

298

299

300

301

302

\section{Future changes of HWs over China}

\subsection{Spatial patterns of future changes}

Fig. 3 shows the projected future changes of compound HWs over China. The frequency, intensity and duration of compound HWs significantly increase all over China, but with different spatial patterns. The increase in frequency of compound HWs over the southern part of China is greater than that over the northern part, particularly with greatest increase on the southwest fringe of mainland China, showing maximum changes of more than 5.0 events per year (Fig. 3a and b). The intensity changes of compound HWs show much larger enhancement over the northern part of China than southern part (Fig. 3c and d). The duration of compound HWs over China extends longer with the largest change (more than 3.0 days) over the southeastern China, the western China, and the southern part of northeastern China (Fig. 3e and f). Interestingly, the compound HWs over the northern China and the Tibetan Plateau show the greatest relative changes in all frequency, intensity, and duration with the largest ratios of these three features in the FP to the PD (Fig. S4), but the frequency and duration of compound HWs over the southern China are of much smaller relative changes though of the largest absolute changes (Fig. 3). The future changes of compound HWs in MetUM-GOML1 and MetUM-GOML2 are consistent with each other. However, there are some slight differences between them. For instance, the increase in frequency over the northwestern China and the enhancement of intensity over northern China in MetUM-GOML2 (Fig. 
3b, d) are a little bit stronger than those in MetUM-GOML1 (Fig. 3a, c). The high value centre of increase in duration over the southern part of China is located in the southeastern part of China in MetUM-GOML1 (Fig. 3e) but in the central southern part in MetUM-GOML2 (Fig. 3f).

Future changes of daytime HWs are shown in Fig. 4. All three features of daytime HWs increase significantly over most part of China. The frequency of daytime HWs increases the most over the northwestern part of China and uniformly over large part of eastern China with value of 1.0-2.0 events per year (Fig. 4a and b). The intensity of daytime HWs is enhanced more evenly than that of compound HWs with relatively high value of more than $0.6^{\circ} \mathrm{C} /$ day over the southern part of China (Fig. $4 \mathrm{c}$ and $\mathrm{d}$ ). The duration of daytime HWs are lengthened over most part of China, particularly with changes of more than 2.0 days being over the northwestern part of China (Fig. 4e and f). The ratios of the frequency, intensity, and duration of daytime HWs in the FP to the PD (Fig. S5) share the similar spatial patterns with the absolute changes of them (Fig. 4). The future changes of daytime HWs are almost the same in the two models with very weak differences between them.

Future changes of nighttime HWs are illustrated in Fig. 5. Similar with the compound and daytime HWs, all three features of nighttime HWs increase significantly over China. The spatial distributions of the increase in frequency and intensity of nighttime HWs are more spatial-uniform comparing to those of the compound HWs. The increase in frequency of nighttime HWs over most part of China is similar in 
magnitude, except the relatively large increase over the southern margin of mainland China (more than 4.0 events per year; Fig. $5 \mathrm{a}$ and b). The changes in intensity of nighttime HWs also show a more or less uniform increase over most part of China with value of $0.3-0.6{ }^{\circ} \mathrm{C} / \mathrm{day}$, apart from the greater enhancement of intensity over the northern margin of mainland China (Fig. $5 \mathrm{c}$ and d). The duration of nighttime HWs extends longer relatively greatly over the Tibetan Plateau and the southeast coast of China with the largest changes of more than 3.0 days over the Tibetan Plateau (Fig. 5e and f). The pattern of relative changes of nighttime HWs (Fig. S6) are similar with those of the absolute changes (Fig. 5), except that the frequency over the northeastern China and the intensity over the southern margin of mainland China show larger relative changes but smaller absolute changes, comparing to other regions. The spatial patterns of future changes of nighttime HWs in MetUM-GOML1 and MetUM-GOML2 are quite similar, despite some differences in intensity of changes, such as larger increases in frequency over the central northern China and stronger enhancement of intensity over northern margin of mainland China in MetUM-GOML2 (Fig. 5b and d).

\subsection{Area averaged future changes}

Fig. 6 shows the area averaged future changes in frequency, intensity, and duration of three types of HWs over whole China and ratios of these three features in the FP projection to the PD in MetUM-GOML1 and MetUM-GOML2. The area averaged future changes and ratios of three types of HWs over China in MetUM-GOML1 in most aspects agree with those in MetUM-GOML2. 

are similar, but the increase in intensity in MetUM-GOML1 is slightly less than that in

MetUM-GOML2. The area averaged future changes in frequency, intensity and duration of compound HWs over the whole mainland China are 3.66 (3.38) events per year, 1.45 (1.94) ${ }^{\circ} \mathrm{C} /$ day, and 2.53 (2.67) days in MetUM-GOML1 (MetUM-GOML2;

Fig. 6a, c, and e). Compared to the compound HWs in the PD, the frequency of compound HWs increases remarkably in the FP, which is about 4-5 times the one in the PD, and the intensity and duration in the FP more or less double the ones in the PD (Fig. $6 b, d$, and f).

For the daytime HWs, the changes in frequency, intensity, and duration over whole China in MetUM-GOML1 are very close to those in MetUM-GOML2, with values of 1.38 events per year, $0.51{ }^{\circ} \mathrm{C} /$ day, and 0.61 days in MetUM-GOML1 relative to those ones of 1.82 events per year, $0.61{ }^{\circ} \mathrm{C} /$ day, and 0.96 days in MetUM-GOML2 (Fig. 6a, c, and e). The future changes of daytime HWs are significant but weaker than those of compound HWs. The frequency of daytime HWs in the FP increases by $60 \%-80 \%$ relative to that in the PD, and the intensity of daytime HWs increases by around $40 \%$, and the duration of daytime HWs increases by $20 \%-30 \%$ (Fig. $6 \mathrm{~b}$, d, and f).

For the nighttime HWs, the changes in intensity over whole China are similar in two models, with value of $0.45{ }^{\circ} \mathrm{C} /$ day in MetUM-GOML1 compared to $0.58{ }^{\circ} \mathrm{C} /$ day in MetUM-GOML2 (Fig. 6c), while the changes in frequency and duration over whole China in MetUM-GOML1, with values of 2.50 events per year and 1.29 days, are about 
3/4 of those in MetUM-GOML2, which are 3.19 events per year and 1.68 days (Fig. 6a and e). The future changes in nighttime HWs are slightly larger than those of daytime HWs, but weaker than those of compound HWs. The frequency of nighttime HWs in the FP almost doubles that in the PD, and the intensity and duration of nighttime HWs in the FP increase by about $50 \%-60 \%$ and $30 \%-50 \%$ respectively relative to those in the PD (Fig. 6b, d, and f).

In order to get more clarity on what these projected future changes of three types of HWs exactly mean in context of past changes, the future changes of HWs over China are compared to the past decadal changes of HWs across the mid-1990s, which are indicated by the differences between PD and EP in observations ( $\mathrm{Su}$ and Dong 2019). Nearly all the projected future changes of the three types of HWs are stronger than their decadal changes across the mid-1990s. Specifically, the projected future changes relative to PD in frequency of compound HWs and all three aspects of daytime HWs are 2-4 times the decadal changes across the mid-1990s in observations. The future increase in duration of compound HWs and frequency and duration of nighttime HWs are $20 \%-80 \%$ stronger than their decadal counterparts. These results suggest people will encounter much fiercer changes of HWs over China in the near future than they have experienced across the mid-1990s.

Summarizing the results above, all the compound, daytime, and nighttime HWs over China are projected to occur more frequently with strengthened intensity and elongated duration in the future. Quantitatively, the increases in all three aspects of 
390

391

392

393

394

395

396

397

398

399

400

401

402

403

404

405

406

407

408

409

410

compound HWs in the FP are the most remarkable with the frequency being 4-5 times that in the PD and the intensity and duration nearly doubling those in the PD. The increases in all three aspects of daytime and nighttime HWs are also considerable, with those of nighttime HWs larger than those of daytime HWs. The results of MetUMGOML1 and MetUM-GOML2 are similar in terms of spatial patterns and area averaged quantities of the future changes in the three types of HWs over China, suggesting these projected changes are robust at least for the two models used in this study.

\subsection{Contributions of changes in mean state and variability to future changes of} HWs

Changes in HWs can arise from both a shift of the temperature distribution and changes in temperature variability, such as a widening of the temperature distribution (Meehl and Tebaldi, 2004; Schar et al., 2004; Lau and Nath, 2014; Schoetter et al., 2015, Argueso et al. 2016; Guirguis et al., 2018). These studies suggested that both factors will contribute to heat wave changes in future and indicated an important role of temperature variability in shaping future HWs over North America and Europe. However, the role of shift in temperature distribution and change in temperature variability on future HWs changes over China have not studied. So, the respective contributions of them to the future changes of HWs over China projected in the two models are assessed in this subsection.

Fig. 7 illustrates the future changes in extended summer mean surface air temperatures. Tmax increases by more than $1.5^{\circ} \mathrm{C}$ over most part of China, with three 
high value centres of increase over the southern, northwestern, and northeastern China (Fig. 7a and b). Tmin increases more or less uniformly over most part of China by more than $1.5^{\circ} \mathrm{C}$, but with relatively large increases over the northern margin of mainland China and relatively small increases over the southern margin of mainland China (Fig. 7c and d). All these main features of changes in Tmax and Tmin are similar in both models despite some slight differences. The increase centre of Tmax over the southern China locates in the southeastern China in MetUM-GOML1 but in the central southern China in MetUM-GOML2 (Fig. 7a and b). The increase in Tmin in MetUM-GOML2 is greater than that in MetUM-GOML1 over the southern and northern margins of mainland China (Fig. 7c and d). What should be mentioned, the spatial patterns of future changes of the three types of HWs are consistent with those of surface air temperatures. For instance, the increase centres of intensity and duration of compound and daytime HWs over the southern China in the two models (Fig. 3c-f and 4c-f) corresponds well with the increase centres of Tmax (Fig. 7a and b). The large increase in the intensity of compound and nighttime HWs over the northern margins of mainland China (Fig. 3cd and 5c-d) coheres to the great increase in Tmin over that region (Fig. 7c and d).

To obtain the mean temperature change induced and temperature variabilitychange induced future changes of HWs separately, the HWs in the future related to the mean temperature changes are obtained based on constructed daily surface air temperatures (Tmax and Tmin) by adding the climatological differences in extended summer mean surface air temperatures between the C-FP and C-PD experiments (Fig. 7) to daily surface air temperatures in the C-PD experiments. Then the temperature 
variability-change induced future changes of HWs are obtained by subtracting the mean temperature change induced future changes of HWs from the total future changes of HWs, which refer to the difference between the C-FP and C-PD experiments.

Fig. 8 shows the total, mean temperature change induced, and temperature variability-change induced future changes of three types of HWs averaged over whole mainland China in MetUM-GOML1 and MetUM-GOML2. The future changes of HWs predominantly result from the mean temperature change, which accounts for more than $79 \%$ of the total future changes. The spatial patterns of various properties in three types of HWs induced by the mean temperature change and temperature variability-change are also examined (not shown). The results of spatial patterns are consistent with the area averaged ones. The spatial patterns of the mean temperature change induced future changes of HWs are quite similar with those of the total future changes (Fig. 3-5) and the temperature variability-change induced future changes of HWs are weak and only significant over small sub-regions.

These results above indicate that the changes in mean temperature play a predominant role in shaping future changes of HWs over China in MetUM-GOML1 and MetUM-GOML2. These are in agreement with Argueso et al. (2016) who showed that seasonal mean temperature changes control future changes in heat waves in large areas across the globe by using CMIP5 simulations. The subtle differences in future changes of HWs in the two models also result from the slight differences in future changes of mean state. The physical processes responsible for the future changes in the 
mean surface air temperatures and subsequently the future changes of the three types of HWs are discussed in next section.

\section{Physical processes responsible for the simulated future changes of HWs}

The spatial patterns of future extended-summer-mean changes of some key variables in MetUM-GOML1 and MetUM-GOML2 are illustrated in Fig. 9 and 10. The main features of changes of the physical variables in the two models are similar. The most important features are increased surface downward longwave (LW) radiations everywhere (Fig. 9a and b), partly induced by the increase in GHG concentrations via the greenhouse effect and partly induced by the increase in water vapor in the atmosphere (Fig. 10a and b). The relatively large increase of downward LW radiation by about $7-9 \mathrm{~W} \mathrm{~m}^{-2}$ over the eastern part of China is consistent with large increase of water vapor in the atmosphere by more than $3 \mathrm{~kg} \mathrm{~m}^{-2}$, where the moisture transport from ocean to land is enhanced (not shown) due to strengthened East Asian Summer Monsoon (EASM) and more evaporation of the ocean under the warming climate. Both the increased GHG concentrations and decreased AA emissions increase the land-sea thermal contrast by warming land more than ocean and enhance the EASM (not shown).

This response of circulation is consistent with the previous studies (Lau and Kim 2017;

Lau et al. 2017). The relatively large increases in surface downward LW radiation over the northern margin of China by $9-11 \mathrm{~W} \mathrm{~m}^{-2}$ are mainly the direct impacts of increased greenhouse effect (Fig. 9a and b) since the increase in water vapor in the atmosphere here is relatively small than other regions (Fig. 10a and b) and land surface and 
atmospheric feedbacks are weak due to the very dry underlying surface (Dong et al. 2009).

The changes of net surface shortwave (SW) radiation indicate an increase over most part of China (Fig. 9c and d). This increase is contributed to by the increase of surface clear SW radiation over southeastern and northeastern China (Fig. 9e and f) and the positive anomalies of shortwave cloud radiative effect (SW CRE) over most part of China (Fig. 9g and h). The increase of surface clear SW radiation over southeastern and northeastern China is induced by the reduction of total aerosol optical depth (AOD; Fig. $10 \mathrm{c}$ and d) through aerosol-radiation interaction, which is primarily due to the decrease of sulfur dioxide emissions (Fig. 1).

The positive anomalies of SW CRE over most part of China (Fig. 9g and h) result from both the decrease in cloud cover over most part of China (Fig. 10e and f) and the change of cloud radiative property due to the reduction of aerosol emissions over southeastern and northeastern China through cloud albedo effect of aerosol-cloud interaction (Twomey 1977). From the perspective of change of cloud radiative property, the decrease in aerosol emissions over southeastern and northeastern China leads to an increase in the cloud droplet size (not shown) and a decrease in the cloud droplet number concentration (not shown), resulting in the decrease in the reflectance of clouds and the positive anomalies of SW CRE relative to the high aerosol emissions during PD. From the perspective of decrease in cloud cover, different physical processes are responsible for the decreases in cloud cover over different sub-regions. Over 

514 future.

northwestern China, the reduction of cloud cover is induced by decrease in relative humidity (Fig. 10g and h), which under the global warming scenario is attributed to that water vapor in the atmosphere over land is mainly controlled by transport from ocean and constrained by ocean warming and increases less than saturation specific humidity following the Clausius-Clapeyron relationship because stronger warming over land than over ocean (e.g., Dong et al. 2009; Boé and Terray 2014). Over southeastern China, the cloud cover is decreased by cloud lifetime effect of aerosol-cloud interaction (Albrecht 1989). Over northeastern China, the reduction of cloud cover is caused by both decrease in relative humidity and cloud lifetime effect of aerosol-cloud interaction.

In summary, the surface air temperature during extended summer over China in the mid- $21^{\text {st }}$ century is raised by the increase in surface downward LW radiation related to the enhanced greenhouse effect and the increased water vapor in the atmosphere over China, resulting from the enhanced EASM and increased evaporation from ocean, and by the increase in surface SW radiation related to the decreased cloud cover over most part of China and the decreased AOD southeastern and northeastern China. These physical processes responsible for the future increases in surface air temperature over China are almost the same in MetUM-GOML1 and MetGOML2. As a result, all three aspects of compound, daytime, and nighttime HWs over China would increase in the

The slight differences in the changes of seasonal mean surface air temperature between MetUM-GOML1 and MetUM-GOML2 are induced by the differences in the 
517

increase in surface SW radiation and the increase in surface downward LW radiation, which eventually lead to the subtle differences in the future changes of three types of HWs. The surface SW radiation increases more over the southeastern China in MetUMGOML1 but over the central southern part of China in MetUM-GOML2 (Fig. 9b and c), leading to different locations of maxmum Tmax change over that region (Fig. 7a and $b$ ). The surface downward LW radiation increases more over the northern margin of mainland China and central northern China in MetUM-GOML2 than in MetUMGOML1 (Fig. 9a and b), resulting in large increase in Tmin over these regions. These differences in surface SW radiation and downward LW radiation are attributed to the slight differences in the atmospheric circulations between the two models, since the atmospheric circulations determine the aerosol distribution, water vapor transport and large-scale precipitation, which have direct or indirect effects on the energy budgets.

\section{Conclusions}

The future changes in the compound, daytime, and nighttime HWs over China during extended summer (May-September) in the mid-2 $1^{\text {st }}$ century (FP, 2045-2055) under RCP4.5 scenario relative to present day (PD, 1994-2011) are investigated in the aspects of frequency, intensity, and duration in this study. The numerical experiments performed by two coupled models, comprising the atmospheric components of two state-of-the-art climate models coupled to a multi-level mixed-layer ocean model and having much smaller sea surface temperature biases than fully coupled general circulation models, are used to evaluate the future changes in the HWs and to reveal the 
538

539

540

541

542

543

544

545

546

547

physical processes associated with these changes. The principal results are concluded below.

The three types of HWs over China are projected to be of more frequent occurrence with strengthened intensity and elongated duration under the scenario of increased GHG concentrations and decreased aerosol emissions over Eurasian continent. The change in compound HWs will be the most dramatic in all three aspects, with the frequency in the FP being 4-5 times that in the PD, and the intensity and duration nearly doubling those in the PD. The changes of daytime and nighttime HWs are also remarkable, with the increase of nighttime HWs being larger than those of daytime HWs. The projected future changes of HWs over China are predominantly determined by the changes in seasonal mean surface air temperatures (Tmax and Tmin) with changes in temperature variability playing a minor role in both models.

The surface air temperatures are raised by increased downward LW radiation and increased surface SW radiation, which therefore increases the frequency, intensity, and duration of all three types of HWs over China. The increase in surface downward LW radiation is induced by the enhanced greenhouse effect and the increased water vapor in the atmosphere, resulting from the enhanced EASM and increased ocean evaporation in the warming climate. The increase in surface SW radiation is contributed to, partly by the decreased cloud cover due to the reduced relative humidity in a warming world and partly by the decreased aerosol emissions via direct aerosol-radiation interaction and indirect aerosol-cloud interaction over southeastern and northeastern China. 
MetUM-GOML2 are consistent in terms of spatial pattern and area averaged quantities.

Although slight differences exist in these future changes between two models, the projected increase in frequency, intensity, and duration of the three types of HWs over China under RCP4.5 scenario is robust among the two models used in this study.

Projected future changes of the three types of HWs in the mid- $21^{\text {st }}$ century relative to present day are stronger than their decadal changes across the mid-90s. Specifically, the projected future changes relative to PD in frequency of compound HWs and all three aspects of daytime HWs are 2-4 times of the decadal changes across the mid1990s in observations. The future increase in duration of compound HWs and frequency and duration of nighttime HWs are $20 \%-80 \%$ stronger than their decadal changes across the mid-1990s. These results suggest people will encounter much fiercer changes of HWs over China in the future than they have experienced across the mid-1990s and China would face a challenge to take adaptation measures to cope with the projected frequency increase, intensity enhancement and duration lengthening of HWs.

The future changes of HWs over China in the mid- $21^{\text {st }}$ century are projected under RCP4.5 scenario in this paper. There are some other factors influencing the HWs on the other timescales. For example, the variations of western North Pacific Subtropical High, East Asian Jet Stream, and El Nino-Southern Oscillation have an impact on the interannual variability of the HWs over China (Wang et al., 2013; Wang et al., 2016; Luo and Lau, 2017; Luo and Lau, 2018). These factors should be taken into 
consideration when forecasting the HWs on a shorter time scale.

581

582

583

584

585

586

587

588

589

590

\section{Acknowledgement}

This study is supported by the National Natural Science Foundation of China under Grants 41505037, 41875103, by the Applied Basic Research Foundation of Yunnan Province (2016FB078), and by the UK-China Research \& Innovation Partnership Fund through the Met Office Climate Science for Service Partnership (CSSP) China as part of the Newton Fund. QS is supported by China Scholarship Council. BD is supported by the U.K. National Centre for Atmospheric Science-Climate (NCAS-Climate) at the University of Reading. The authors like to thank three anonymous reviewers for their constructive comments on the earlier version of the paper. 


\section{Reference}

Albrecht, B. A. (1989) Aerosols, cloud microphysics, and fractional cloudiness. Science, 245(4923), 1227-1230, https://doi.org/10.1126/science.245.4923.1227.

Argueso, D., A. Di Luca, S. E. Perkins- Kirkpatrick and J. P. Evans (2016) Seasonal mean temperature changes control future heat waves. Geophys. Res. Lett., 43(14), 7653-7660, https://doi.org/10.1002/2016GL069408.

Arribas, A., M. Glover, A. Maidens, K. Peterson, M. Gordon, C. MacLachlan, R. Graham, D. Fereday, J. Camp and A. Scaife (2011) The GloSea4 ensemble prediction system for seasonal forecasting. Mon. Wea. Rev., 139(6), 1891-1910, https://doi.org/10.1175/2010MWR3615.1.

Black, E., M. Blackburn, G. Harrison, B. Hoskins and J. Methven (2004) Factors contributing to the summer 2003 European heatwave. Weather, 59(8), 217-223, https://doi.org/doi:10.1256/wea.74.04.

Boé, J. and L. Terray (2014) Land-sea contrast, soil-atmosphere and cloud-temperature interactions: interplays and roles in future summer European climate change. Clim. Dyn., 42(3-4), 683-699, https://doi.org/10.1007/s00382-013-1868-8.

Chen, R. D. and R. Y. Lu (2014) Large-scale circulation anomalies associated with 'tropical night' weather in Beijing, China. Int. J. Climatol., 34(6), 1980-1989, https://doi.org/10.1002/joc.3815.

Chen, W. and B. Dong (2018) Anthropogenic impacts on recent decadal change in temperature extremes over China: relative roles of greenhouse gases and anthropogenic aerosols. Clim. Dyn., https://doi.org/10.1007/s00382-018-4342-9.

Chen Y., W. Chen, Q. Su, F. Luo, S. Sparrow, F. Tian, B. Dong, S. F. B. Tett, F. C. Lott, and D. Wallom (2018) Anthropogenic warming has substantially increased the likelihood of July 2017-like heat waves over Central-Eastern China [in "Explaining Extremes of 2017 from a Climate Perspective"]. Acepted by Bull. Amer. Meteor. Soc..

Chen, Y. and Y. Li (2017) An inter-comparison of three heat wave types in China during 1961-2010: Observed basic features and linear trends. Sci. Rep., 7, 45619, https://doi.org/10.1038/srep45619.

Chen, Y. and P. Zhai (2017) Revisiting summertime hot extremes in China during 1961- 2015: overlooked compound extremes and significant changes. Geophys. Res. Lett., 44(10), https://doi.org/10.1002/2016GL072281.

Coumou, D. and S. Rahmstorf (2012) A decade of weather extremes. Nat. Clim. Change, 2(7), 491-496, https://doi.org/10.1038/nclimate1452.

Della-Marta, P. M., J. Luterbacher, H. von Weissenfluh, E. Xoplaki, M. Brunet and H. Wanner (2007) Summer heat waves over western Europe 1880-2003, their relationship to large-scale forcings and predictability. Clim. Dyn., 29(2), 251-275, 
https://doi.org/10.1007/s00382-007-0233-1.

Dong, B., J. M. Gregory and R. T. Sutton (2009) Understanding land-sea warming contrast in response to increasing greenhouse gases. Part I: Transient adjustment. J. Clim., 22(11), 3079-3097, https://doi.org/10.1175/2009JCLI2652.1.

Dong, B., R. T. Sutton, L. Shaffrey and N. P. Klingaman (2017) Attribution of forced decadal climate change in coupled and uncoupled ocean-atmosphere model experiments. J. Clim., 30(16), 6203-6223, https://doi.org/10.1175/jcli-d-160578.1.

Freychet, N., S. Tett, J. Wang and G. Hegerl (2017) Summer heat waves over Eastern China: dynamical processes and trend attribution. Environ. Res. Lett., 12(2), 024015, https://doi.org/10.1088/1748-9326/aa5ba3.

Freychet, N., S. Sparrow, S. F. B. Tett, M. J. Mineter, G. C. Hegerl and D. C. H. Wallom (2018) Impacts of anthropogenic forcings and El Nino on Chinese extreme temperatures. Adv. Atmos. Sci., 35(8), 994-1002, https://doi.org/10.1007/s00376018-7258-8.

Gershunov, A., D. R. Cayan and S. F. Iacobellis (2009) The great 2006 heat wave over California and Nevada: signal of an increasing trend. J. Clim., 22(23), 6181-6203, https://doi.org/10.1175/2009JCLI2465.1.

Guirguis, K., A. Gershunov, D. R. Cayan and D. W. Pierce (2018) Heat wave probability in the changing climate of the Southwest US. Clim. Dyn., 50(9-10), 3853-3864, https://doi.org/10.1007/s00382-017-3850-3.

Gosling, S. N., J. A. Lowe, G. R. McGregor, M. Pelling and B. D. Malamud (2009) Associations between elevated atmospheric temperature and human mortality: a critical review of the literature. Climatic Change, 92(3-4), 299-341, https://doi.org/10.1007/s10584-008-9441-x.

Guo, X., J. Huang, Y. Luo, Z. Zhao and Y. Xu (2017) Projection of heat waves over China for eight different global warming targets using 12 CMIP5 models. Theor. Appl. Climatol., 128(3-4), 507-522, https://doi.org/10.1007/s00704-015-1718-1.

Hatfield, J. L. and J. H. Prueger (2015) Temperature extremes: Effect on plant growth and development. Weather and Climate Extremes, 10, 4-10, https://doi.org/10.1016/j.wace.2015.08.001.

Hirons, L., N. Klingaman and S. Woolnough (2015) MetUM-GOML: a near-globally coupled atmosphere-ocean-mixed-layer model. Geosci. Model Dev., 8, 363-379, https://doi.org/10.5194/gmd-8-363-2015.

Jones, C., et al (2011) The HadGEM2-ES implementation of CMIP5 centennial simulations. Geosci. Model Dev., 4(3), 543-570, https://doi.org/10.5194/gmd-4543-2011.

Karl, T. R. and R. W. Knight (1997) The 1995 Chicago heat wave: How likely is a 
recurrence? Bull. Amer. Meteor. Soc., 78(6), 1107-1120, https://doi.org/10.1175/1520-0477(1997)078<1107:tchwhl $>2.0$. co;2.

Lamarque, J.-F., G. P. Kyle, M. Meinshausen, K. Riahi, S. J. Smith, D. P. van Vuuren, A. J. Conley and F. Vitt (2011) Global and regional evolution of short-lived radiatively-active gases and aerosols in the Representative Concentration Pathways. Climatic Change, 109, 191, https://doi.org/10.1007/s10584-011-01550 .

Lamarque, J.-F., T. C. Bond, V. Eyring, C. Granier, A. Heil, Z. Klimont, D. Lee, C. Liousse, A. Mieville and B. Owen (2010) Historical (1850-2000) gridded anthropogenic and biomass burning emissions of reactive gases and aerosols: methodology and application. Atmos. Chem. Phys., 10(15), 7017-7039, https://doi.org/10.5194/acp-10-7017-2010.

Lau, N.-C., and M. J. Nath (2014) Model simulation and projection of European heat waves in present-day and future climates, J. Clim., 27(10), 3713-3730, https://doi.org/10.1175/jcli-d-13-00284.1.

Lau, W. K. M., K. M. Kim and L. R. Leung (2017) Changing circulation structure and precipitation characteristics in Asian monsoon regions: greenhouse warming vs. aerosol effects. Geosci. Lett., 4(1), 28, https://doi.org/10.1186/s40562-017-00943.

Lau, W. K. M. and K. M. Kim (2017) Competing influences of greenhouse warming and aerosols on Asian summer monsoon circulation and rainfall. Asia-Pac. J. Atmo. Sci., 53(2), 181-194, https://doi.org/10.1007/s13143-017-0033-4.

Lesk, C., P. Rowhani and N. Ramankutty (2016) Influence of extreme weather disasters on global crop production. Nature, 529(7584), 84, https://doi.org/10.1038/nature16467.

Li, Y., Y. Ding and W. Li (2017) Observed trends in various aspects of compound heat waves across China from 1961 to 2015. J. Meteor. Res., 31(3), 455-467, https://doi.org/10.1007/s13351-017-6150-2.

Li, Z., L. J. Cao, Y. N. Zhu and Z. W. Yan (2016) Comparison of two homogenized datasets of daily maximum/mean/minimum temperature in China during 19602013. J. Meteor. Res., 30(1), 53-66, https://doi.org/10.1007/s13351-016-5054-x.

Luo, F., B. Dong, F. Tian and S. Li (2018). Anthropogenically forced decadal change of South Asian summer monsoon across the mid-1990s. Submitted to J. Geophys. Res. Atmos..

Luo, M. and N.-C. Lau (2017) Heat waves in southern China: Synoptic behavior, longterm change, and urbanization effects. J. Clim., 30(2), 703-720, https://doi.org/10.1175/jcli-d-16-0269.1.

Luo, M. and N.-C. Lau (2018) Synoptic characteristics, atmospheric controls, and longterm changes of heat waves over the Indochina Peninsula. Clim. Dyn., 51(7-8), 
2707-2723, https://doi.org/10.1007/s00382-017-4038-6.

Ma, S. M., T. J. Zhou, D. A. Stone, O. Angelil and H. Shiogama (2017) Attribution of the July-August 2013 heat event in Central and Eastern China to anthropogenic greenhouse gas emissions. Environ. Res. Lett., 12(5), https://doi.org/10.1088/1748-9326/aa69d2.

Meehl, G. A. and C. Tebaldi (2004) More intense, more frequent, and longer lasting heat waves in the 21st Century. Science, 305(5686), 994-997, https://doi.org/10.1126/science.1098704.

Moss, R. H., J. A. Edmonds, K. A. Hibbard, M. R. Manning, S. K. Rose, D. P. Vuuren, Van, T. R. Carter, E. Seita, K. Mikiko and K. Tom (2010) The next generation of scenarios for climate change research and assessment. Nature, 463(7282), 747756, https://doi.org/10.1038/nature08823.

Perkins, S. E. (2015) A review on the scientific understanding of heatwaves-Their measurement, driving mechanisms, and changes at the global scale. Atmos. Res., 164-165, 242-267, https://doi.org/10.1016/j.atmosres.2015.05.014.

Perkins, S. E. and L. V. Alexander (2013) On the measurement of heat waves. J. Clim., 26(13), 4500-4517, https://doi.org/10.1175/jcli-d-12-00383.1.

Rayner NA, Parker DE, Horton EB, Folland CK, Alexander LV, Rowell DP, Kent EC, Kaplan A (2003) Global analyses of SST, sea ice and night marine air temperature since the late nineteenth century. J Geophys Res 108. doi:10.1029/2002JD002670

Robine, J.-M., S. L. K. Cheung, S. Le Roy, H. Van Oyen, C. Griffiths, J.-P. Michel and F. R. Herrmann (2008) Death toll exceeded 70,000 in Europe during the summer of 2003. C. R. Biol., 331(2), 171-178, https://doi.org/10.1016/j.crvi.2007.12.001.

Seneviratne, S. I., M. G. Donat, B. Mueller and L. V. Alexander (2014) No pause in the increase of hot temperature extremes. Nat. Clim. Change, 4(3), 161, https://doi.org/10.1038/nclimate2145.

Schär, C., P. L. Vidale, D. Lüthi, C. Frei, C. Häberli, M. A. Liniger, and C. Appenzeller (2004), The role of increasing temperature variability in European summer heatwaves, Nature, 427(6972), 332-336, https://doi.org/10.1038/nature02300.

Schoetter, R., J. Cattiaux and H. Douville (2015) Changes of western European heat wave characteristics projected by the CMIP5 ensemble. Clim. Dyn., 45(5-6), 16011616, https://doi.org/10.1007/s00382-014-2434-8.

Smith, D. M. and J. M. Murphy (2007) An objective ocean temperature and salinity analysis using covariances from a global climate model. J. Geophys. Res. Oceans, 112(C2), https://doi.org/10.1029/2005JC003172.

Sparrow, S., Q. Su, F. X. Tian, S. H. Li, Y. Chen, W. Chen, F. F. Luo, N. Freychet, F. C. Lott, B. W. Dong, S. F. B. Tett and D. Wallom (2018) Attributing human influence on the July 2017 Chinese heatwave: the influence of sea-surface temperatures. 
Environ. Res. Lett., 13(11), https://doi.org/10.1088/1748-9326/ade356.

Stefanon, M., D. A. Fabio and D. Philippe (2012) Heatwave classification over Europe and the Mediterranean region. Environ. Res. Lett., 7(1), 014023, https://doi.org/10.1088/1748-9326/7/1/014023.

Su, Q. and B. Dong (2019) Recent decadal changes in heat waves over China: drivers and mechanisms. Submitted to J. Clim..

Sun, Y., L. Song, H. Yin, B. Zhou, T. Hu, X. Zhang and P. Stott (2016) Human influence on the 2015 extreme high temperature events in Western China [in "Explaining Extremes of 2015 from a Climate Perspective"]. Bull. Amer. Meteor. Soc., 97(12), S102-S106, https://doi.org/10.1175/bams-d-16-0158.1.

Sun, Y., X. B. Zhang, F. W. Zwiers, L. C. Song, H. Wan, T. Hu, H. Yin and G. Y. Ren (2014) Rapid increase in the risk to extreme summer heat in Eastern China. Nat. Clim. Change, 4(12), 1082-1085, https://doi.org/10.1038/nclimate2410.

Tan, J., Y. Zheng, G. Song, L. S. Kalkstein, A. J. Kalkstein and X. Tang (2007) Heat wave impacts on mortality in Shanghai, 1998 and 2003. Int. J. Biometeorol., 51(3), 193-200, https://doi.org/10.1007/s00484-006-0058-3.

Tian, F., B. Dong, J. Robson and R. Sutton (2018) Forced decadal changes in the East Asian summer monsoon: the roles of greenhouse gases and anthropogenic aerosols. Clim. Dyn., 1-17, https://doi.org/10.1007/s00382-018-4105-7.

Twomey, S. (1977) Influence of pollution on shortwave albedo of clouds. J. Atmos. Sci., 34(7), 1149-1152, https://doi.org/10.1175/15200469(1977)034<1149:tiopot>2.0.co;2.

Walters, D., M. Best, A. Bushell, D. Copsey, J. Edwards, P. Falloon, C. Harris, A. Lock, J. Manners and C. Morcrette (2011) The Met Office Unified Model global atmosphere 3.0/3.1 and JULES global land 3.0/3.1 configurations. Geosci. Model Dev., 4(4), 919, https://doi.org/10.5194/gmd-4-919-2011.

Walters, D., N. Wood, S. Vosper and S. Milton (2014) ENDGame: A new dynamical core for seamless atmospheric prediction. Met Office documentation, can be consulted http://www.metoffice.gov.uk/media/pdf/s/h/ENDGameGOVSciv2.0.pdf.

Walters, D., M. Brooks, I. Boutle, T. Melvin, R. Stratton, S. Vosper, H. Wells, K. Williams, N. Wood and T. Allen (2017) The Met Office unified model global atmosphere 6.0/6.1 and JULES global land 6.0/6.1 configurations. Geosci. Model Dev., 10(4), 1487-1520, https://doi.org/10.5194/gmd-10-1487-2017.

Wang, C., L. Zhang, S.-K. Lee, L. Wu, and C. R. Mechoso (2014) A global perspective on CMIP5 climate model biases. Nat. Clim. Change, 4, 201-205, doi:https://doi.org/10.1038/nclimate2118.

Wang, P., J. Tang, X. Sun, S. Wang, J. Wu, X. Dong and J. Fang (2017) Heatwaves in 
China: definitions, leading patterns and connections to large-scale atmospheric circulation and SSTs. J. Geophys. Res. Atmos., 122(20), https://doi.org/10.1002/2017JD027180.

Wang, W., W. Zhou, X. Li, X. Wang and D. Wang (2016) Synoptic-scale characteristics and atmospheric controls of summer heat waves in China. Clim. Dyn., 46(9), 29232941, https://doi.org/10.1007/s00382-015-2741-8.

Wang, W., W. Zhou, X. Wang, S. K. Fong and K. C. Leong (2013) Summer high temperature extremes in Southeast China associated with the East Asian jet stream and circumglobal teleconnection. J. Geophys. Res. Atmos., 118(15), 8306-8319, https://doi.org/10.1002/jgrd.50633.

Wilbanks, T. J. and S. Fernandez (2014) Climate change and infrastructure, urban systems, and vulnerabilities: Technical report for the US department of energy in support of the national climate assessment, Island Press.

Wilcox, L. J., B. Dong, R. T. Sutton and E. J. Highwood (2015) The 2014 hot, dry summer in Northeast Asia [in "Explaining Extremes of 2014 from a Climate Perspective"]. Bull. Amer. Meteor. Soc., 96(12), S105-S110, https://doi.org/10.1175/bams-d-15-00123.1.

You, Q. L., Z. H. Jiang, L. Kong, Z. W. Wu, Y. T. Bao, S. C. Kang and N. Pepin (2017) A comparison of heat wave climatologies and trends in China based on multiple definitions. Clim. Dyn., 48(11), 3975-3989, https://doi.org/10.1007/s00382-0163315-0.

Yu, R., P. M. Zhai and Y. Y. Lu (2018) Implications of differential effects between 1.5 and 2 degrees $\mathrm{C}$ global warming on temperature and precipitation extremes in China's urban agglomerations. Int. J. Climatol., 38(5), 2374-2385, https://doi.org/10.1002/joc.5340.

Zhou, B., Q. H. Wen, Y. Xu, L. Song and X. Zhang (2014a) Projected changes in temperature and precipitation extremes in China by the CMIP5 multimodel ensembles. J. Clim., 27(17), 6591-6611, https://doi.org/10.1175/jcli-d-13-00761.1.

Zhou, T. J., S. M. Ma and L. W. Zou (2014b) Understanding a hot summer in Central Eastern China: summer 2013 in context of multimodel trend analysis [in "Explaining Extremes of 2013 from a Climate Perspective"]. Bull. Amer. Meteor. Soc., 95(9), S54-S57. 
815 Table 1. Summary of numerical experiments

\begin{tabular}{|c|c|c|c|}
\hline Abv. & Experiment & Ocean & Radiative forcing \\
\hline Ro & Relaxation run & $\begin{array}{l}\text { Relaxation to "present day" } \\
\text { (PD, 1994-2011) mean 3D } \\
\text { ocean temperature and } \\
\text { salinity to diagnose } \\
\text { climatological temperature } \\
\text { and salinity tendencies }\end{array}$ & $\begin{array}{l}\text { PD greenhouse gases } \\
\text { (GHGs) over 1994 2011 } \\
\text { and anthropogenic } \\
\text { aerosol (AA) emissions } \\
\text { over 1994 2010 with } \\
\text { AA after } 2006 \text { from } \\
\text { RCP4.5 } \\
\text { (Lamarque et al. 2010, } \\
\text { 2011) }\end{array}$ \\
\hline C-EP & $\begin{array}{l}\text { Early period (EP } \\
1964 \sim 1981)\end{array}$ & & $\begin{array}{l}\text { EP mean GHG and EP } \\
\text { mean AA emissions }\end{array}$ \\
\hline C-PD & $\begin{array}{l}\text { Present day (PD } \\
\text { 1994 2011) }\end{array}$ & and salinity tendencies & $\begin{array}{l}\text { PD mean GHG and PD } \\
\text { mean AA emissions }\end{array}$ \\
\hline C-FP & $\begin{array}{l}\text { future period } \\
(\mathrm{FP}, 2045-2055)\end{array}$ & & $\begin{array}{ll}\mathrm{RCP} 4.5 & \text { emission } \\
\text { scenario } & \end{array}$ \\
\hline
\end{tabular}


Annual sulfur dioxide (2045-2055 minus 1994-2010)

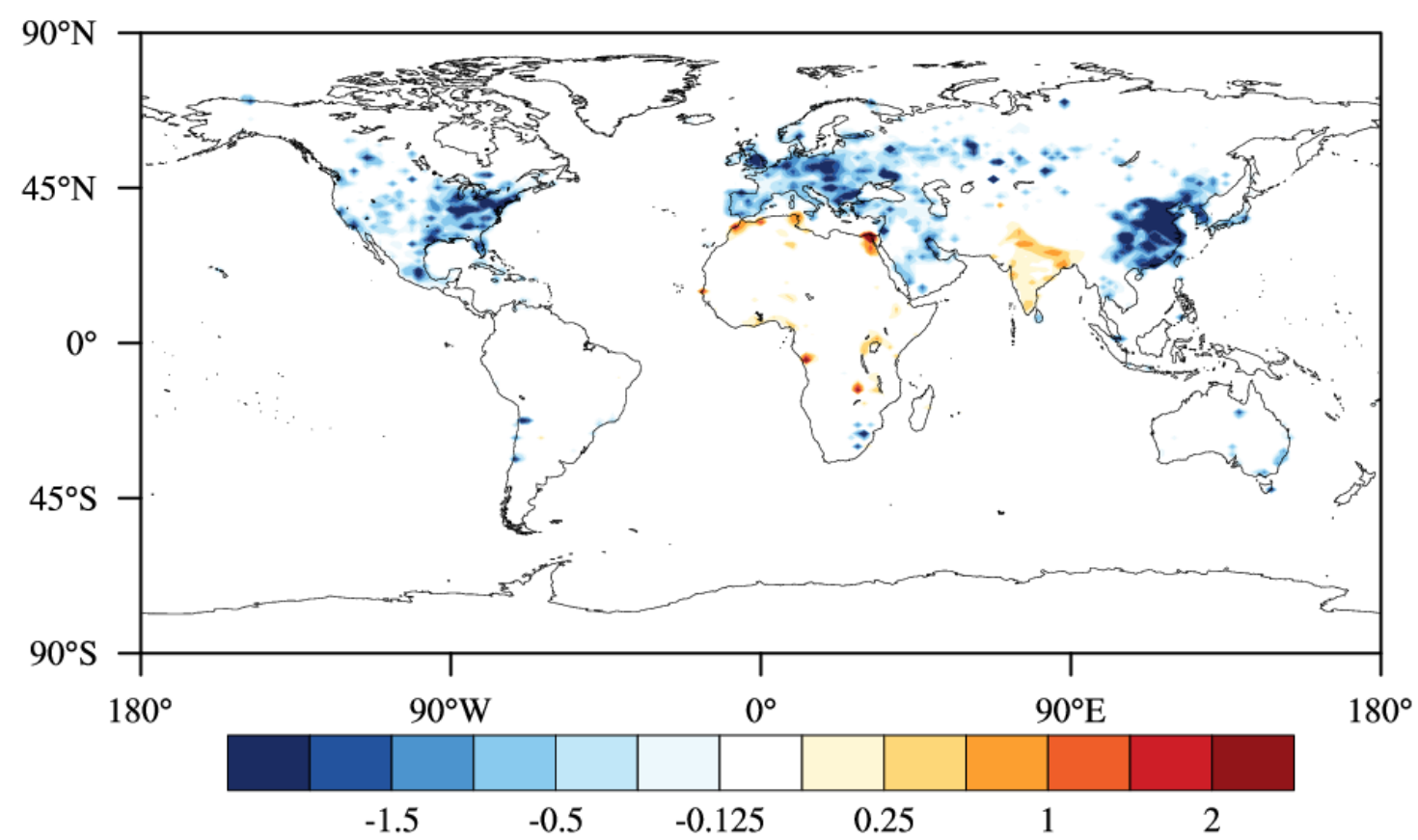

820 Figure 1. Future changes in annual mean sulfur dioxide emissions (units: $\mathrm{g} \mathrm{m}^{-2} \mathrm{yr}^{-1}$ ) during the

821 mid-2 $1^{\text {st }}$ century relative to the PD of 1994-2010.

822 
(a) Tmax mean in OBS

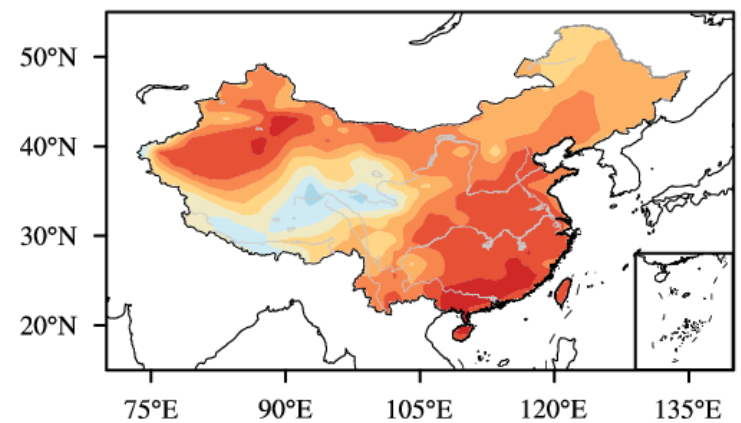

(c) Tmax mean in GOML1

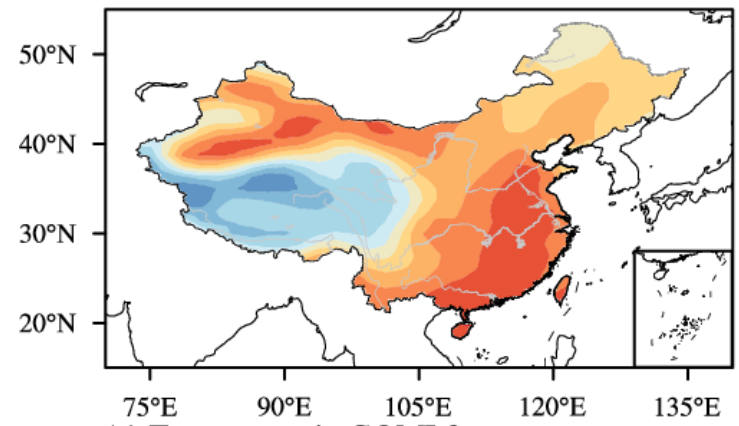

(e) Tmax mean in GOML2

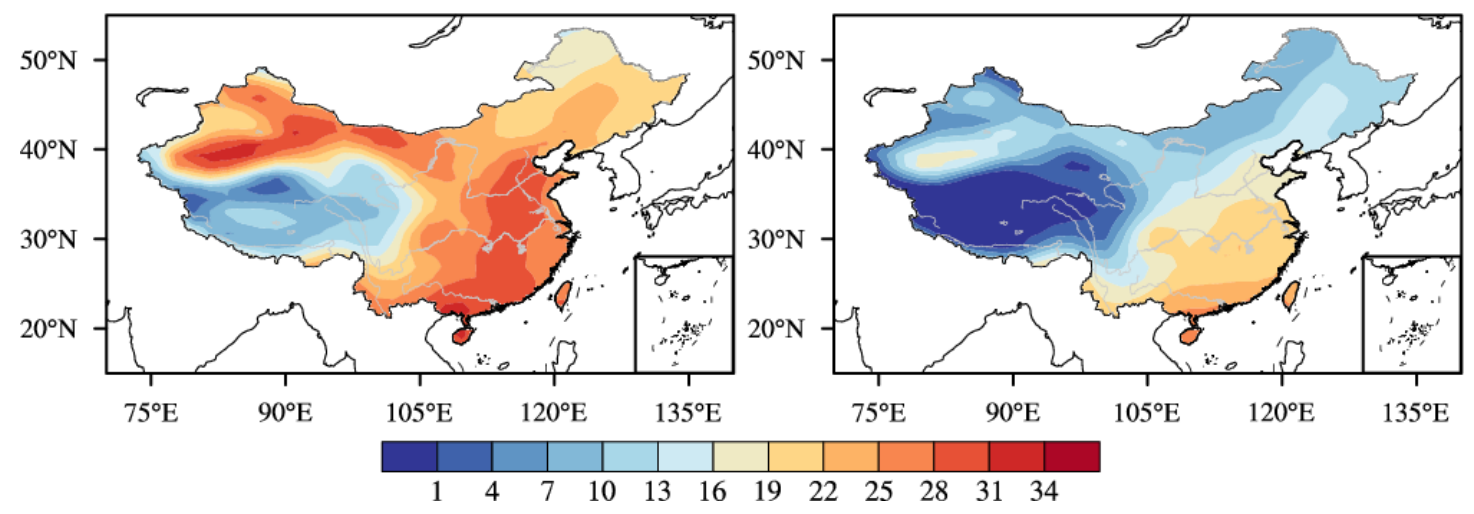

(b) Tmin mean in OBS

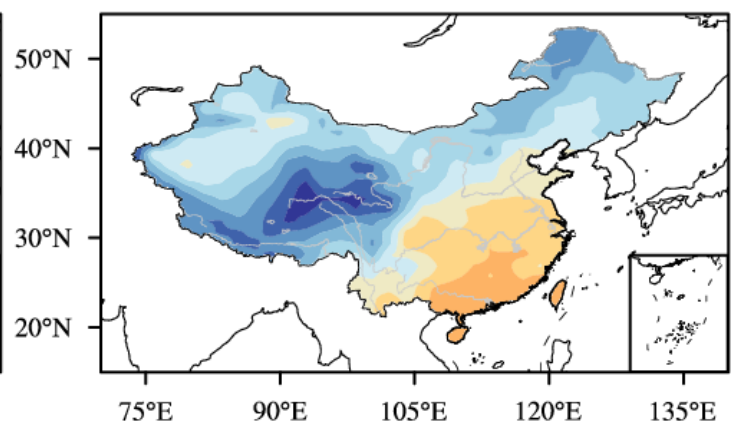

(d) Tmin mean in GOML1

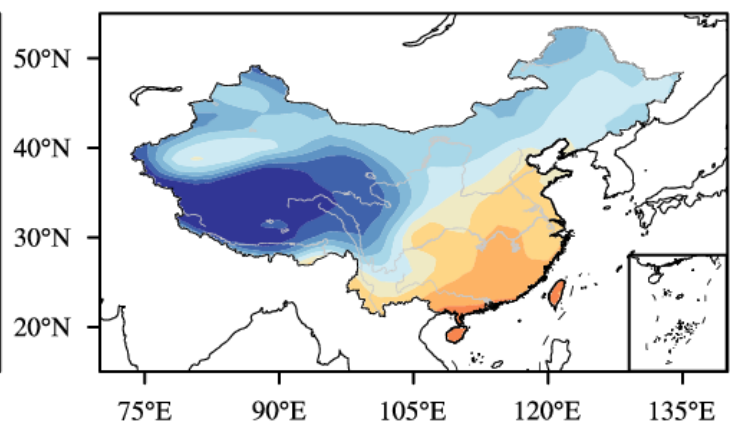

(f) Tmin mean in GOML2
823

824

Figure 2. Climatological means of extended-summer-mean (May-September) Tmax and Tmin during the EP (1964-1981) in observations (a and b) and in the C-EP experiment of MetUM-

GOML1 (c and d) and MetUM-GOML2 (e and f). Units are in ${ }^{\circ} \mathrm{C}$. 


\section{Compound HWs}

(a) Frequency (GOML1)

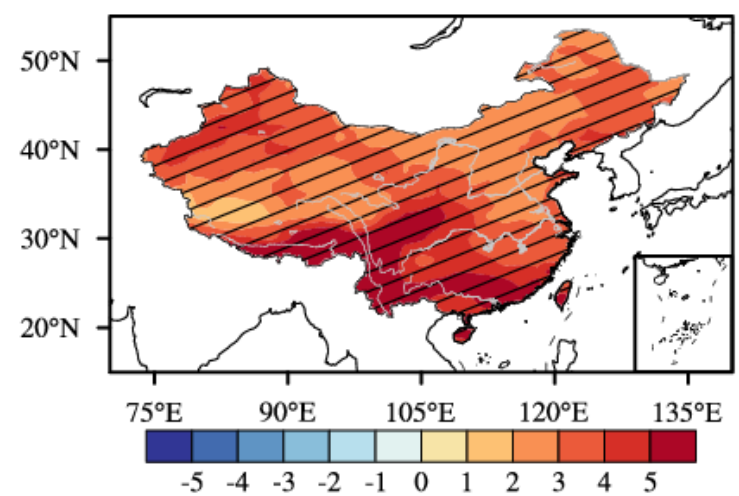

(c) Intensity (GOML1)

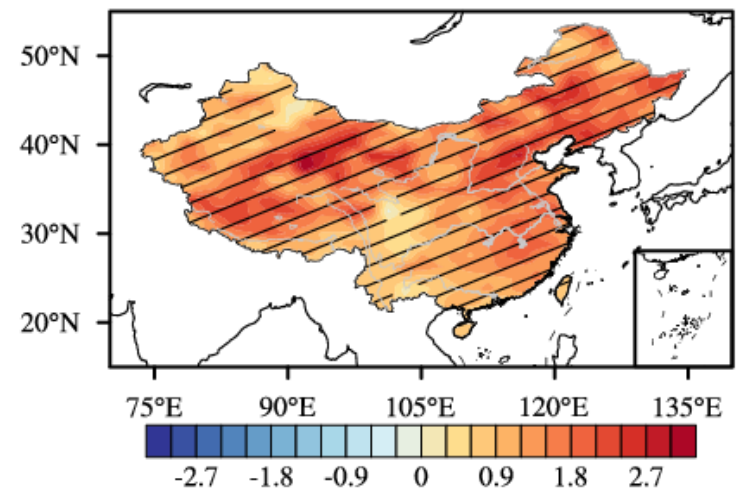

(e) Duration (GOML1)

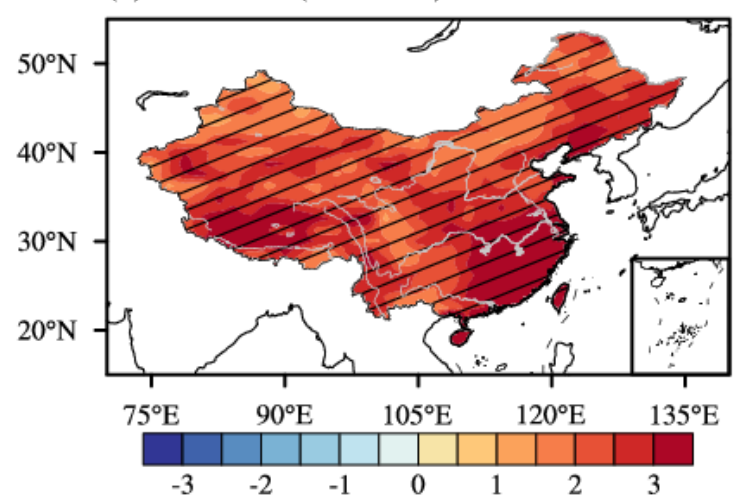

(b) Frequency (GOML2)

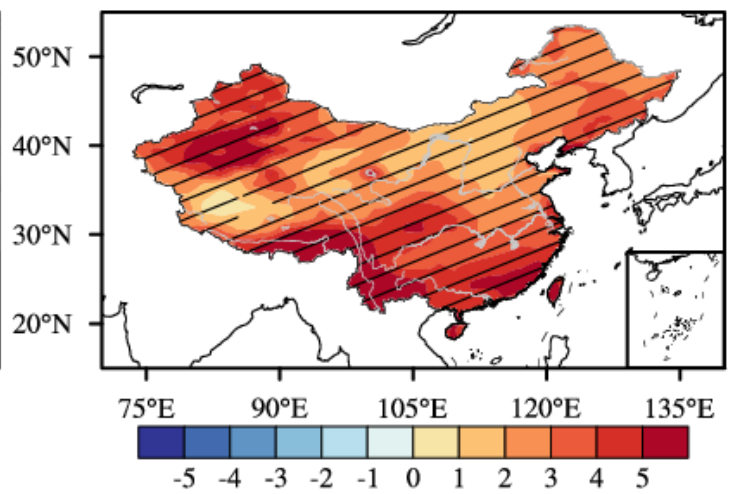

(d) Intensity (GOML2)

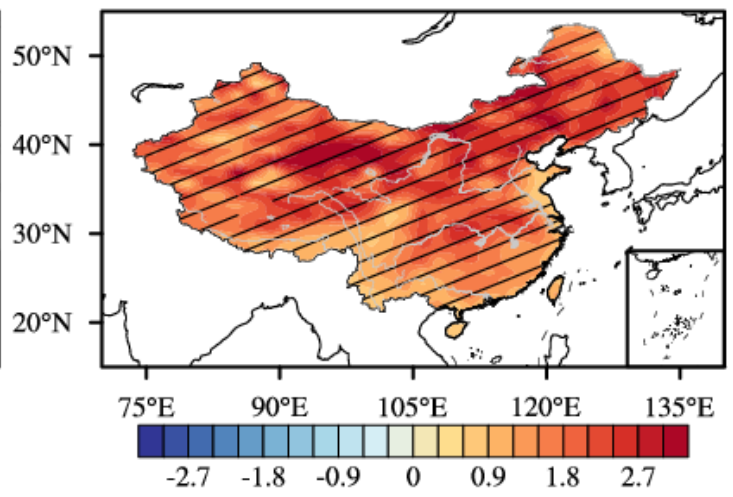

(f) Duration (GOML2)

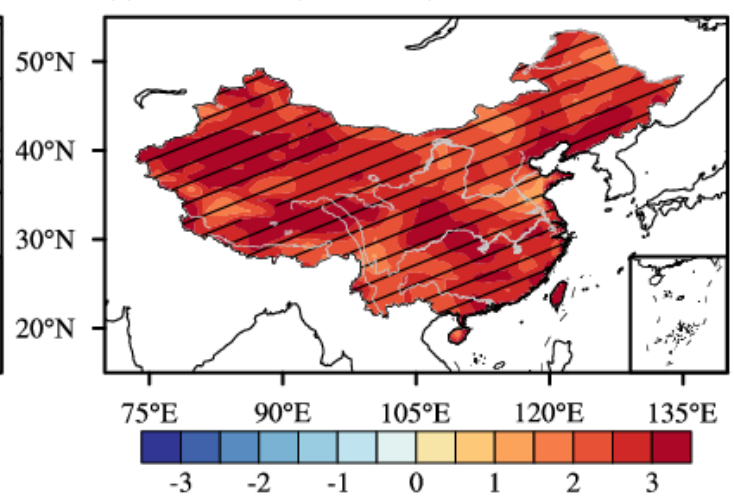

829 Figure 3. Spatial patterns of future changes in frequency (units: events/year; a and b), intensity

830 (units: ${ }^{\circ} \mathrm{C} /$ day; $\mathrm{c}$ and d), and duration (units: days; e and f) of compound HWs in MetUM-GOML1

831 (left panels) and MetUM-GOML2 (right panels), masked by China boundary. The slashes highlight

832 the regions where the differences are statistically significant at the $90 \%$ confidence level based on

833 a two-tailed Student's $t$-test. 


\section{Daytime HWs}

(a) Frequency (GOML1)

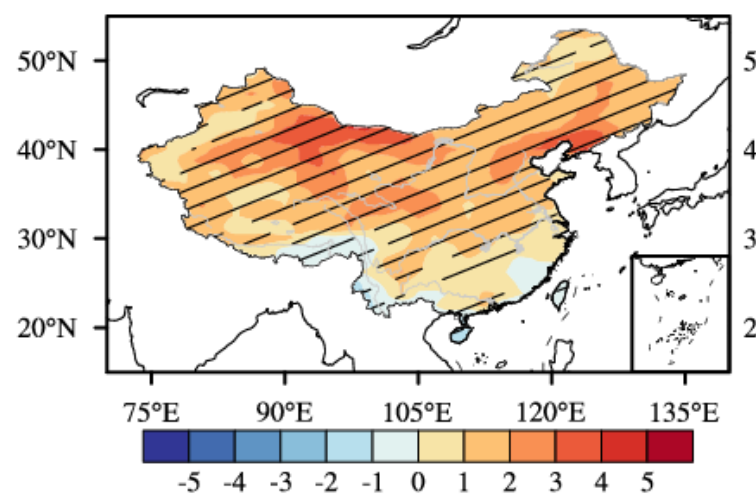

(c) Intensity (GOML1)

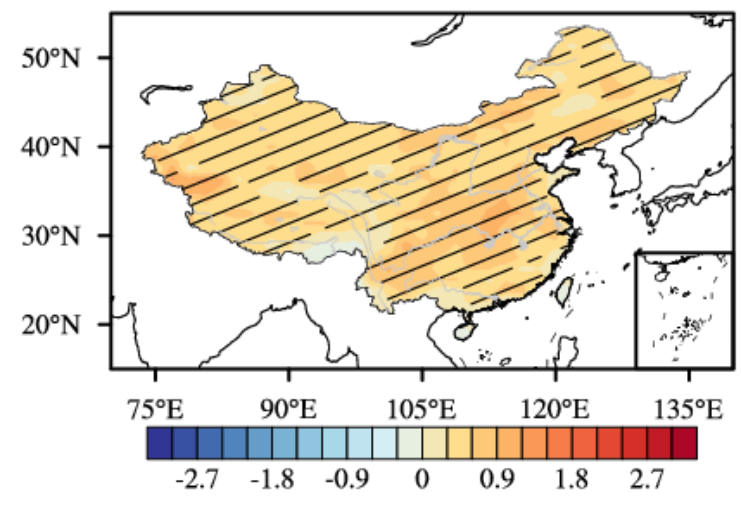

(e) Duration (GOML1)

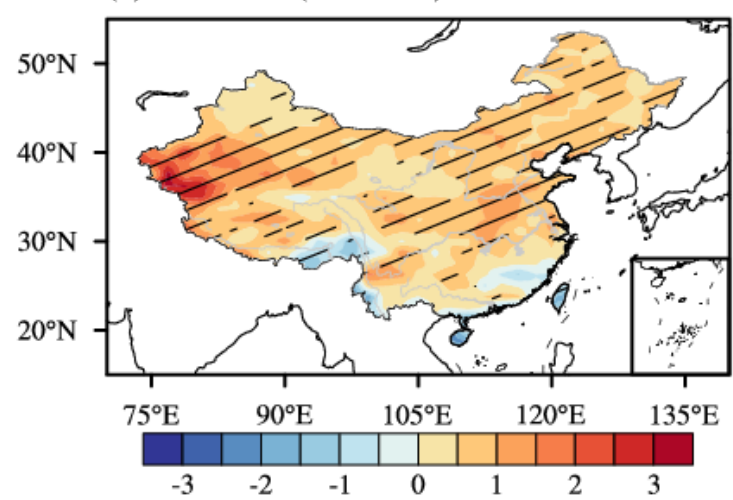

(b) Frequency (GOML2)

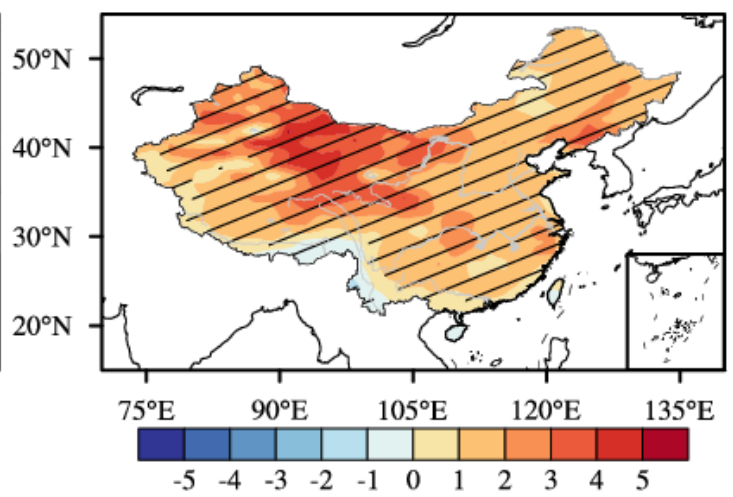

(d) Intensity (GOML2)

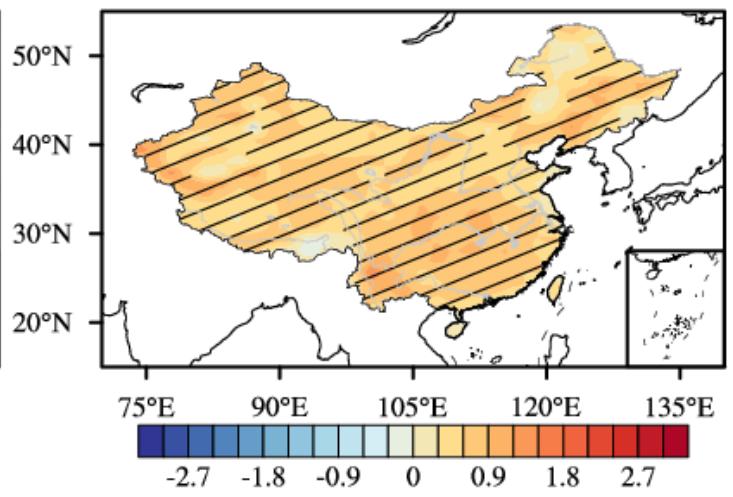

(f) Duration (GOML2)

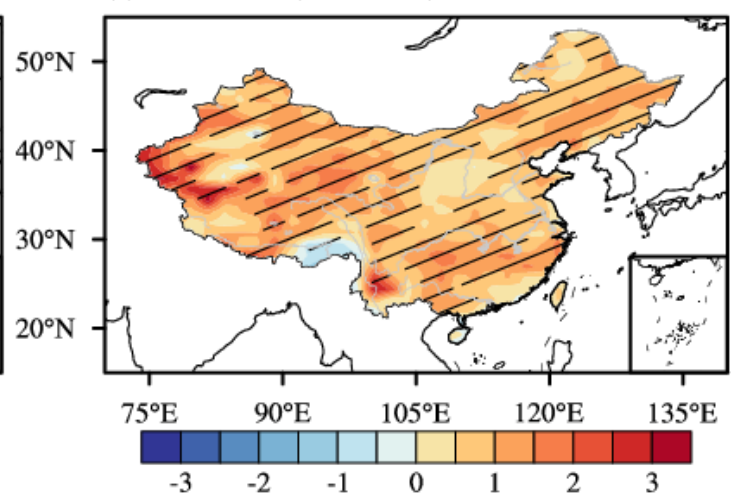

836 Figure 4. Spatial patterns of future changes in frequency (units: events/year; a and b), intensity

837 (units: ${ }^{\circ} \mathrm{C} /$ day; $\mathrm{c}$ and d), and duration (units: days; e and f) of daytime HWs in MetUM-GOML1

838 (left panels) and MetUM-GOML2 (right panels), masked by China boundary. The slashes highlight

839 the regions where the differences are statistically significant at the $90 \%$ confidence level based on

840 a two-tailed Student's $t$-test. 


\section{Nighttime HWs}

(a) Frequency (GOML1)

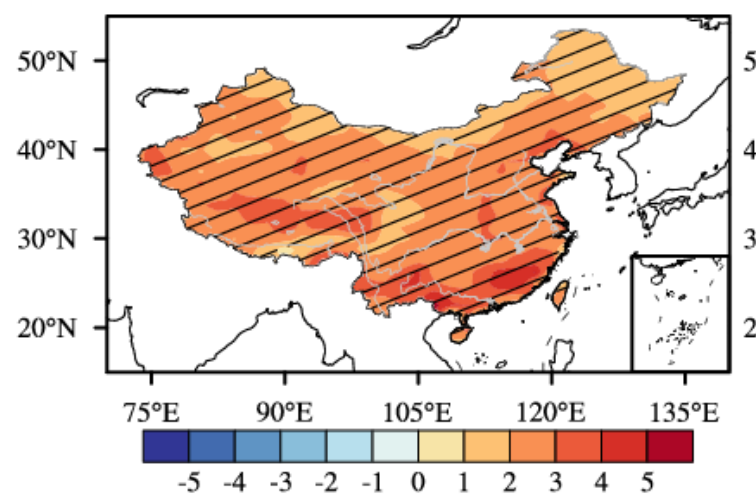

(c) Intensity (GOML1)

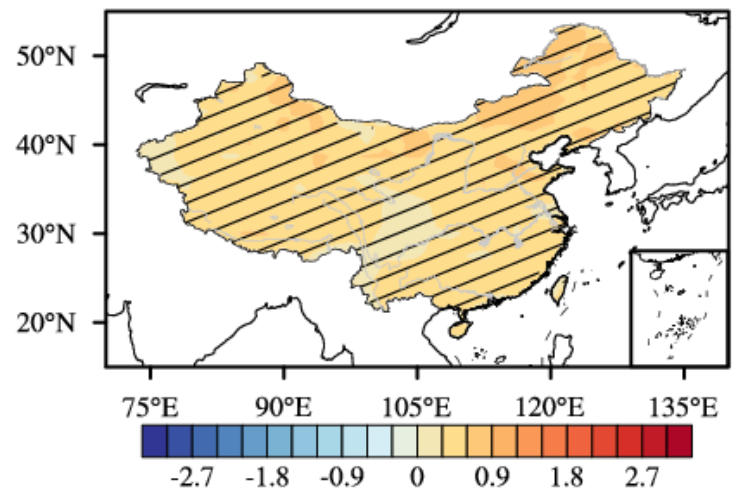

(e) Duration (GOML1)

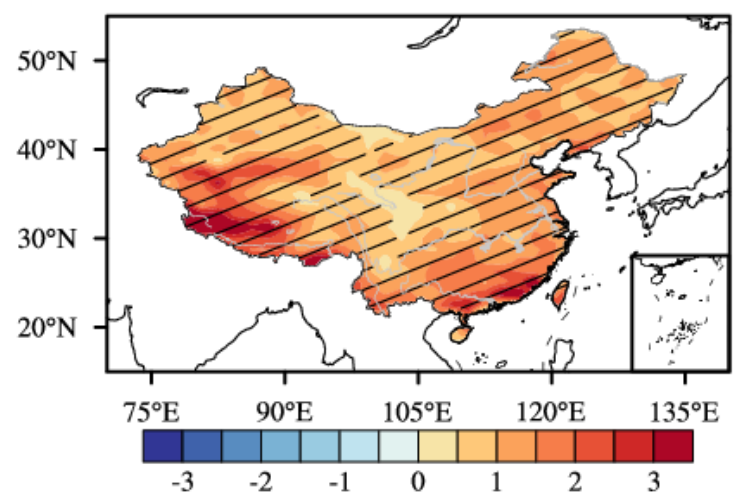

(b) Frequency (GOML2)

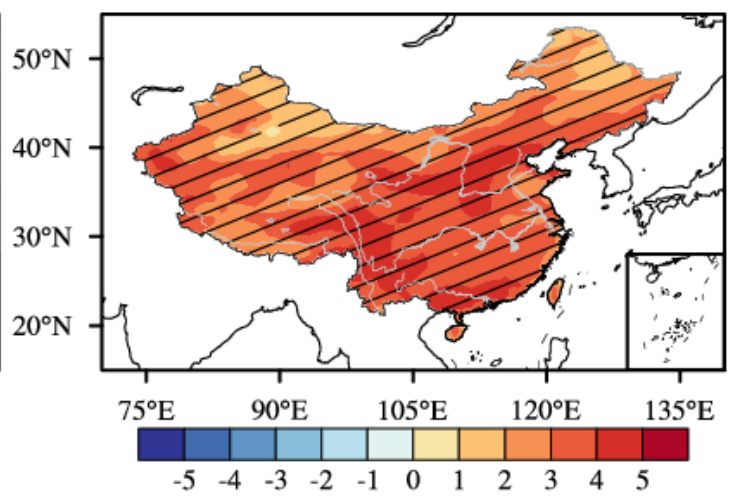

(d) Intensity (GOML2)

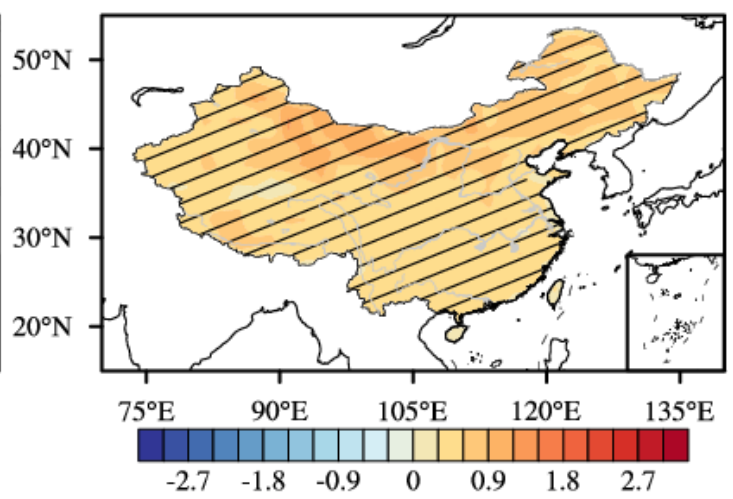

(f) Duration (GOML2)

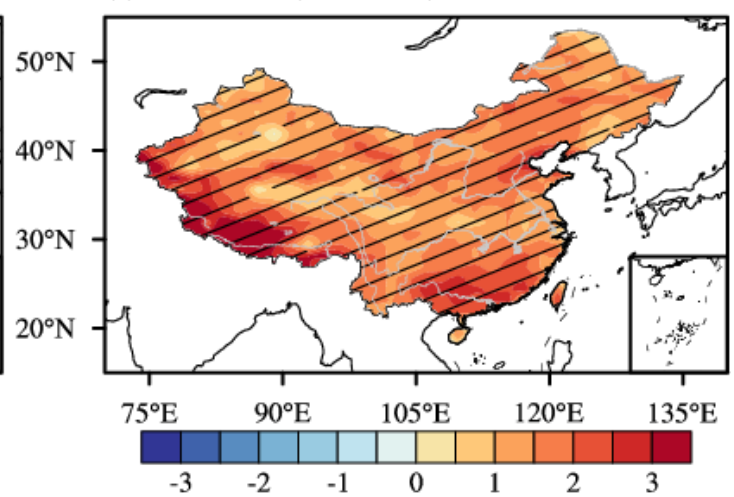

Figure 5. Spatial patterns of future changes in frequency (units: events/year; a and b), intensity

844 (units: ${ }^{\circ} \mathrm{C} /$ day; $\mathrm{c}$ and d), and duration (units: days; e and f) of nighttime HWs in MetUM-GOML1

845 (left panels) and MetUM-GOML2 (right panels), masked by China boundary. The slashes highlight

846 the regions where the differences are statistically significant at the $90 \%$ confidence level based on 
(a) Frequency (changes)

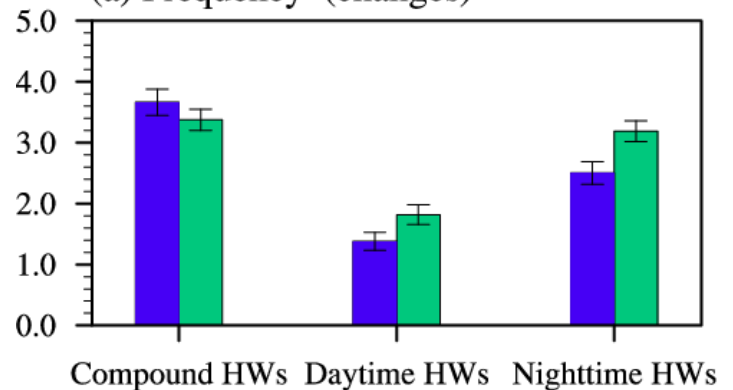

(c) Intensity (changes)

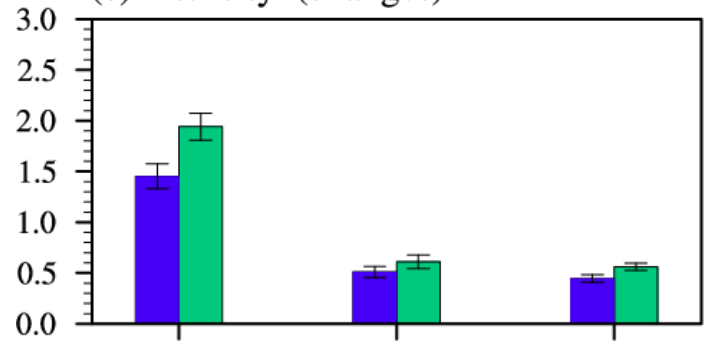

Compound HWs Daytime HWs Nighttime HWs

(e) Duration (changes)

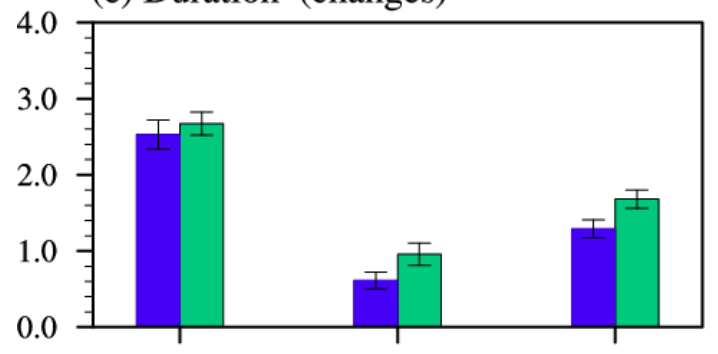

Compound HWs Daytime HWs Nighttime HWs (b) Frequency (ratios)

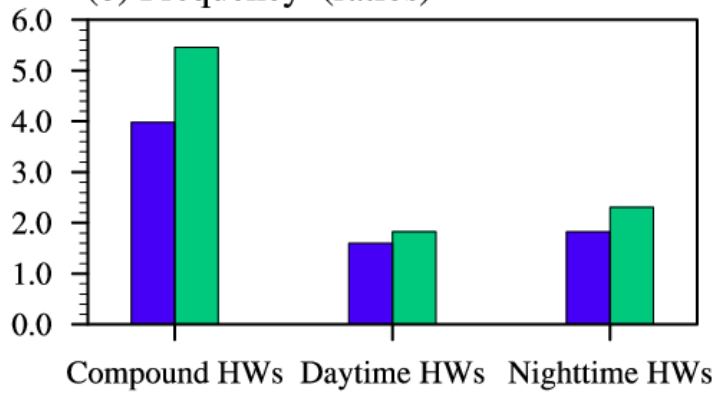

(d) Intensity (ratios)
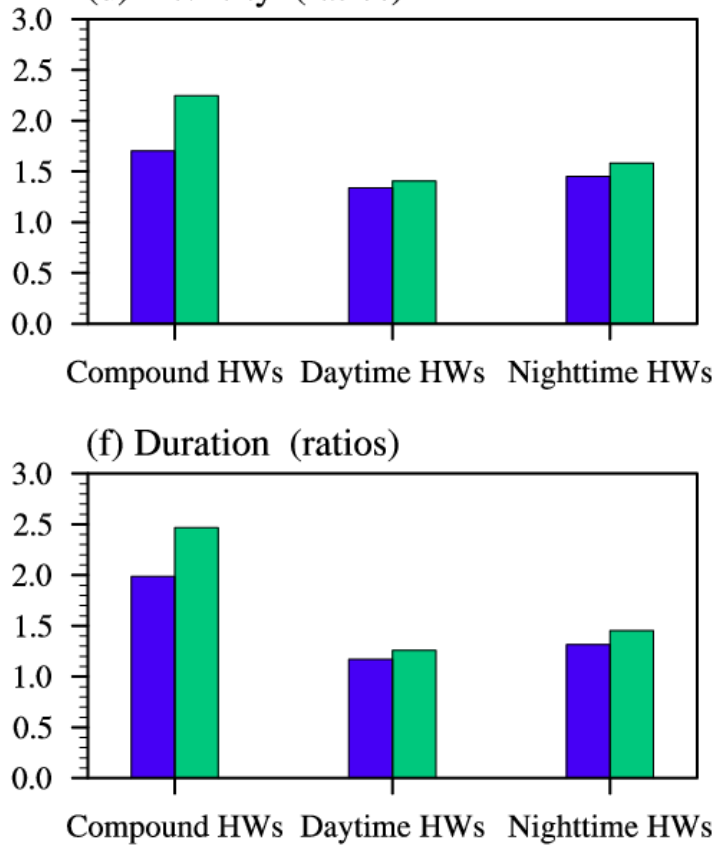

GOML2

Figure 6. Area averaged future changes of frequency (a), intensity (c), and duration (e) of compound, daytime, and nighttime HWs over whole China and the ratios of these three features in the FP

853 projection to the PD (b, d, and f) in MetUM-GOML1 and MetUM-GOML2. Units for frequency,

854 intensity, and duration are events/year, ${ }^{\circ} \mathrm{C} /$ day, and days, respectively. The error bars indicate the $90 \%$ confidence intervals based on two-tailed Student's $t$-test. 
(a) Tmax (GOML1)

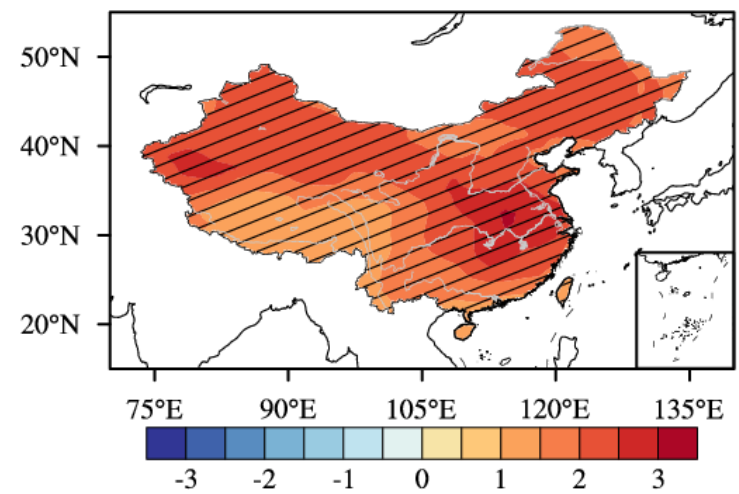

(c) Tmin (GOML1)

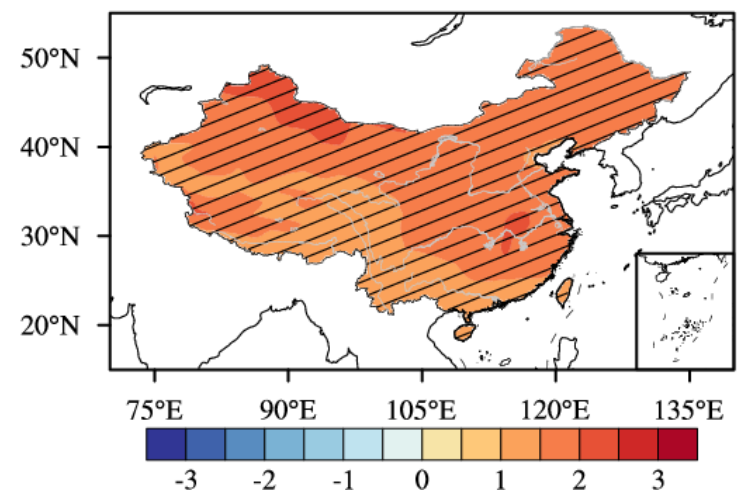

(b) Tmax (GOML2)

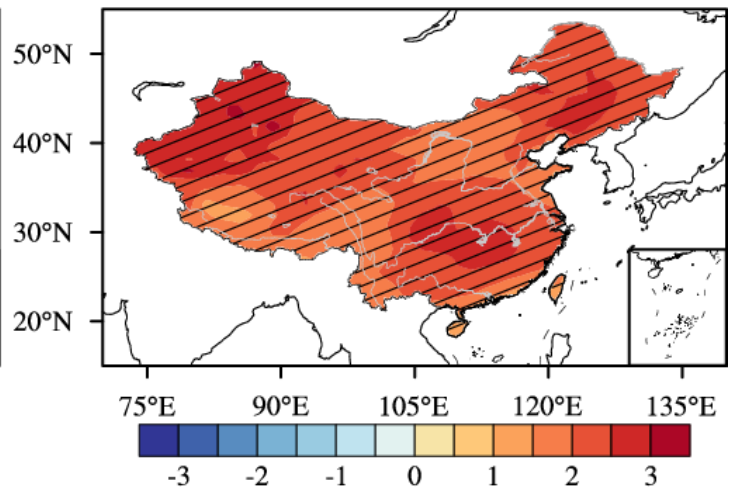

(d) Tmin (GOML2)

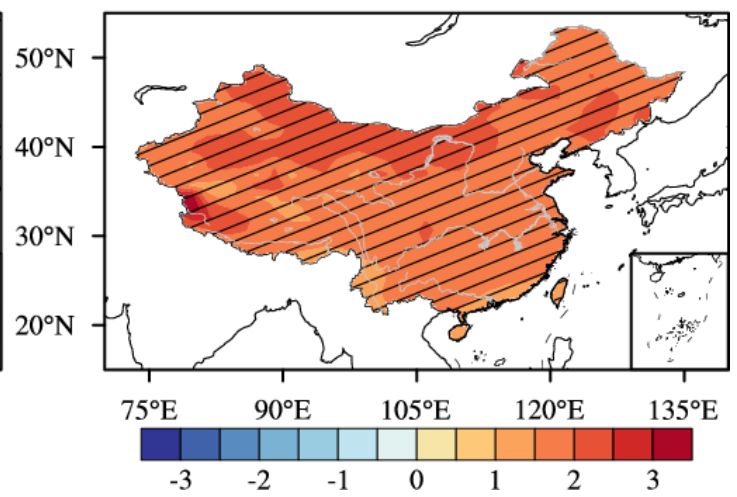

857 Figure 7. Future changes in the extended-summer-mean (May-September) Tmax and Tmin relative

858 to PD simulations in MetUM-GOML1 (a and c) and MetUM-GOML2 (b and d). Units are in ${ }^{\circ} \mathrm{C}$.

859 The slashes highlight the regions where the differences are statistically significant at the $90 \%$ confidence level based on a two-tailed Student's $t$-test. 
(a) Frequency (GOML1)

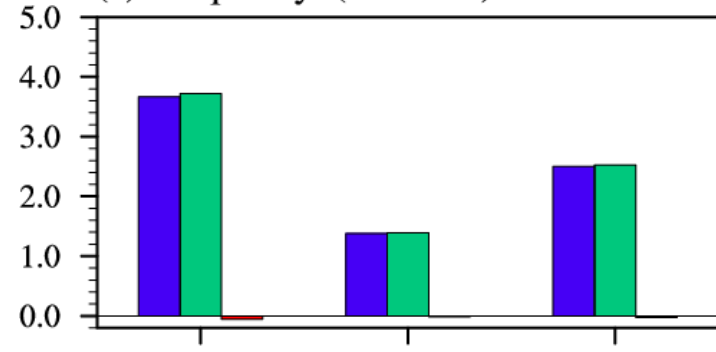

Compound HWsDaytime HWs Nighttime HWs

(c) Intensity (GOML1)

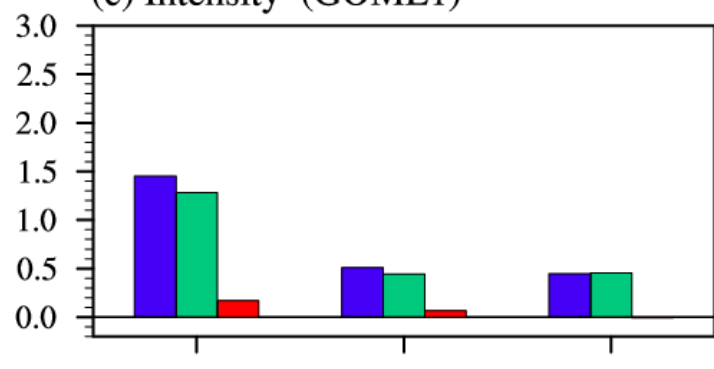

Compound HWsDaytime HWs Nighttime HWs

(e) Duration (GOML1)

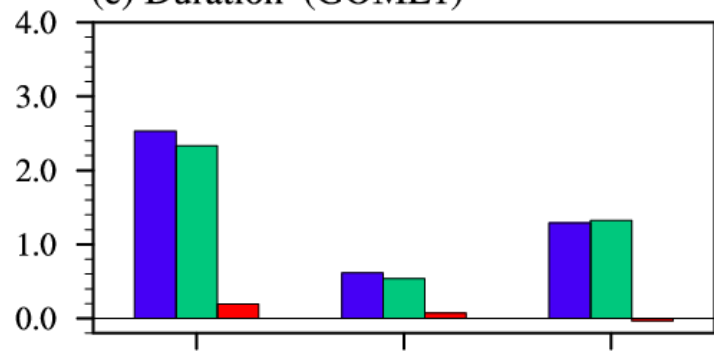

Compound HWsDaytime HWs Nighttime HWs (b) Frequency (GOML2)

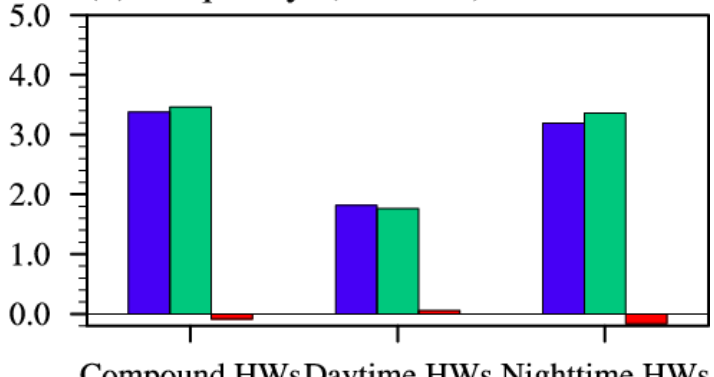

(d) Intensity (GOML2)

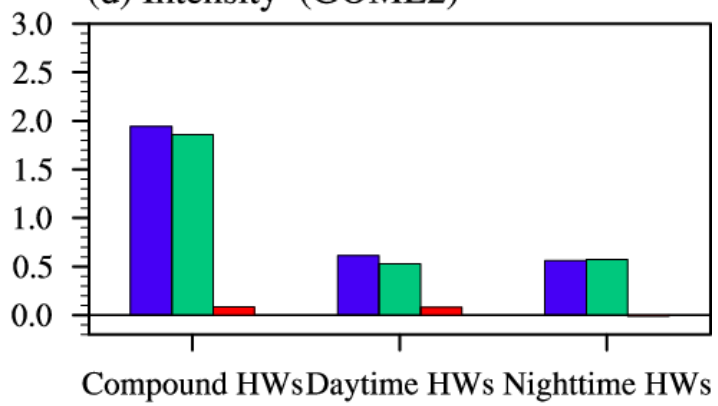

(f) Duration (GOML2)

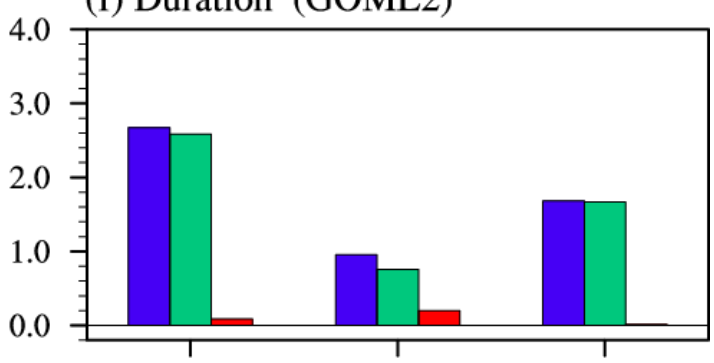

Compound HWsDaytime HWs Nighttime HWs

Mean

Variability

864 Figure 8. Area averaged total, mean temperature change induced, temperature variability-change

865 induced future changes in frequency (units: events/year; a and b), intensity (units: ${ }^{\circ} \mathrm{C} /$ day; $\mathrm{c}$ and d),

866 and duration (units: days; e and f) of compound, daytime, and nighttime HWs over whole China in

MetUM-GOML1 (left panels) and MetUM-GOML2 (right panels). 
(a) Surface downward LW (GOML1)

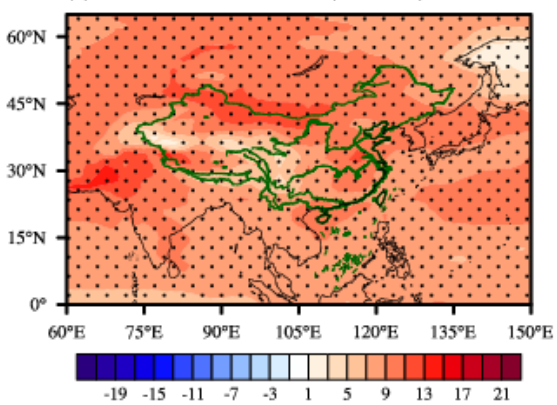

(c) Surface SW (GOML1)

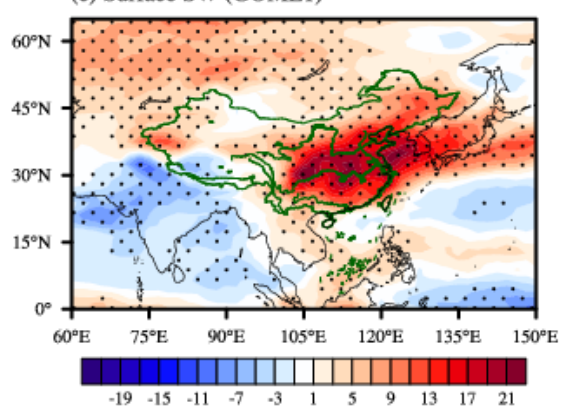

(e) Surface clear SW (GOML1)

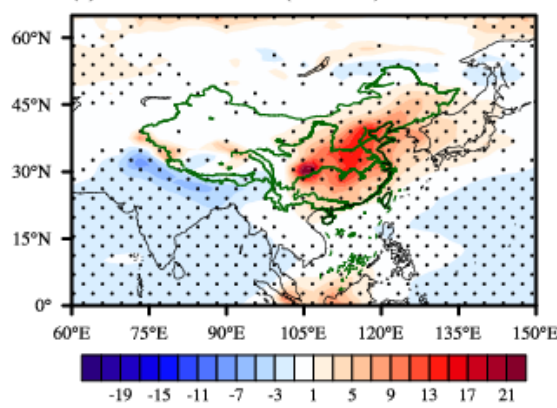

(g) Surface SW CRE (GOML1)

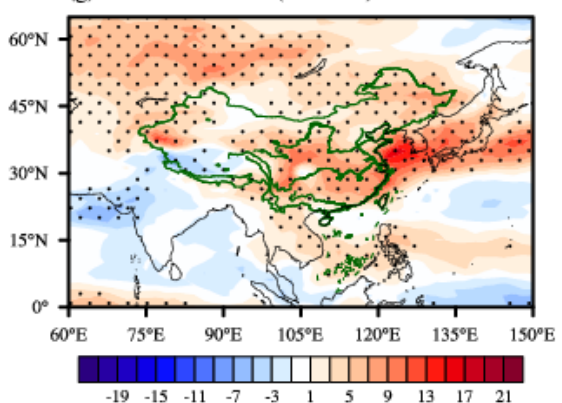

(b) Surface downward LW (GOML2)

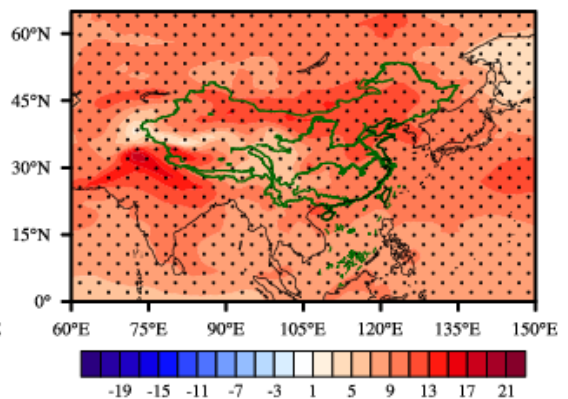

(d) Surface SW (GOML2)

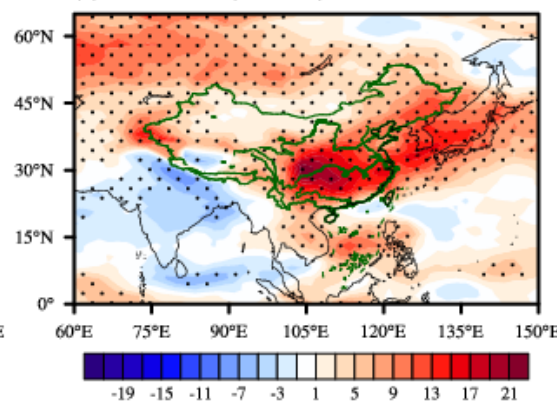

(f) Surface clear SW (GOML2)

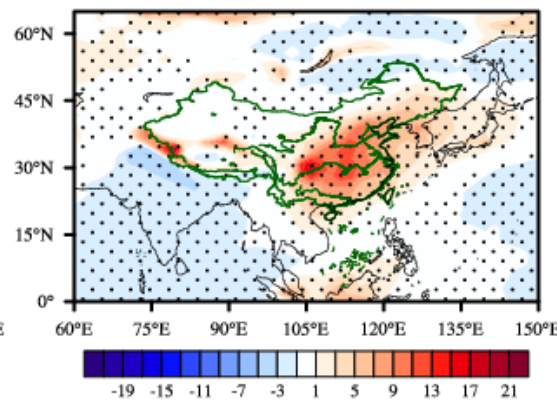

(h) Surface SW CRE (GOML2)

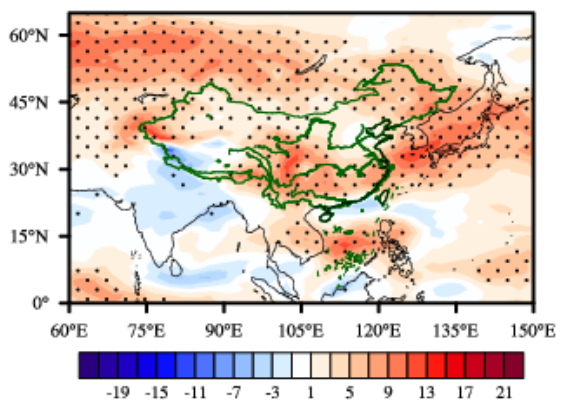

870 Figure 9. Spatial patterns of future extended-summer-mean changes in surface downward LW

871 radiation (a and b), net surface SW radiation (c and d), surface clear SW radiation (e and f), and

872 surface SW CRE (g and h) in MetUM-GOML1 (left panels) and MetUM-GOML2 (right panels).

873 Radiation with positive value meaning downward and in $\mathrm{W} \mathrm{m}^{-2}$. The black dots highlight regions

874 where the changes are statistically significant at the $90 \%$ confidence level based on a two-tailed

875 Student's $t$-test. 
(a) Water vapor (GOML1)

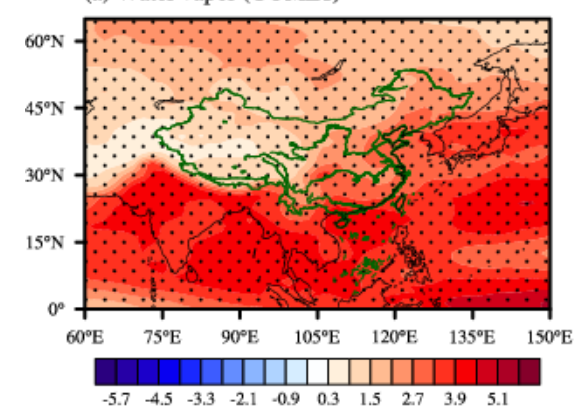

(c) Total AOD at 0.55 um (GOML1)

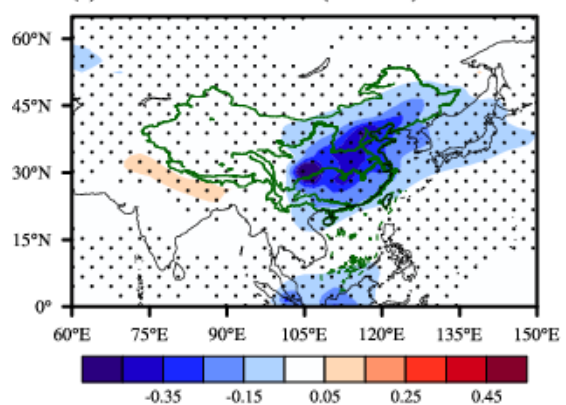

(e) Total cloud (GOML1)

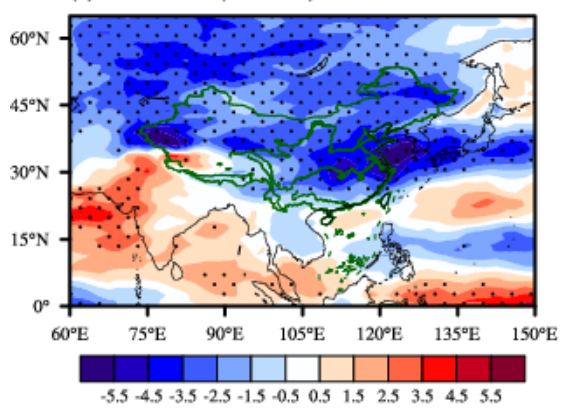

(g) Relative humidity at $700 \mathrm{hPa}$ (GOML1)

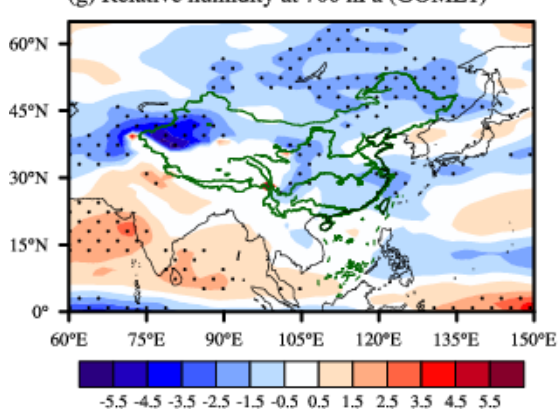

(b) Water vapor (GOML2)

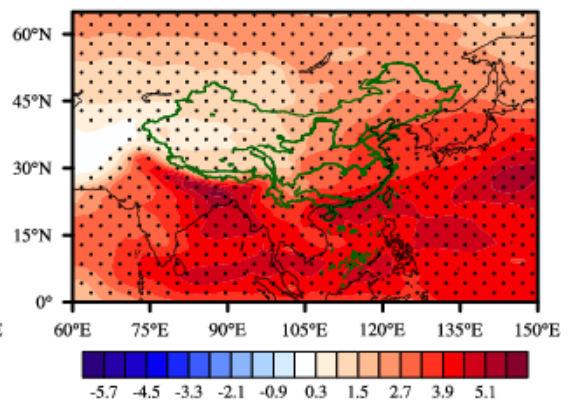

(d) Total AOD at 0.55 um (GOML2)

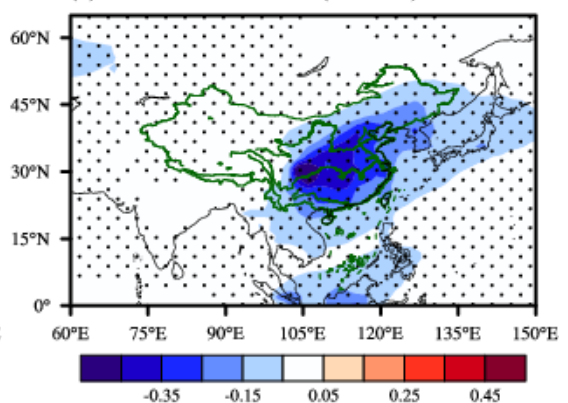

(f) Total cloud (GOML2)

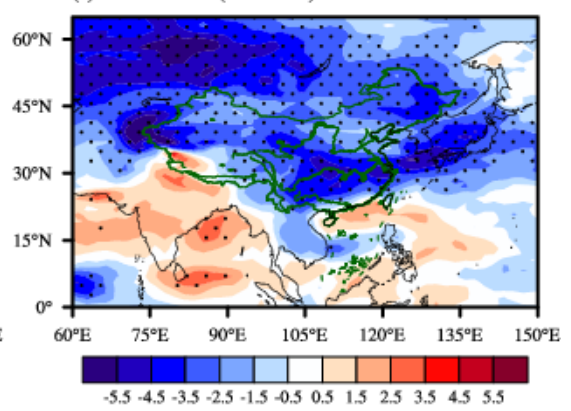

(h) Relative humidity at $700 \mathrm{hPa}$ (GOML2)

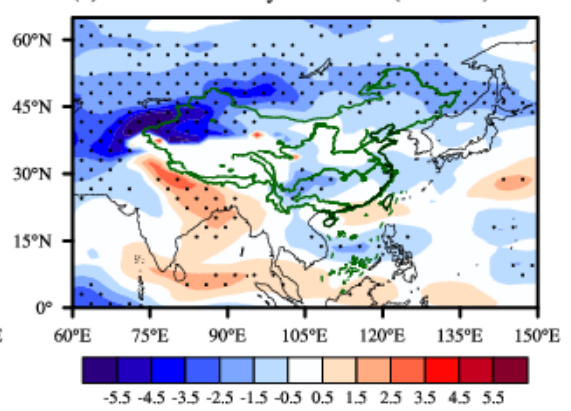

Figure 10. Spatial patterns of future extended-summer-mean changes in column-integrated water

879 vapor ( $\mathrm{a}$ and b; units: $\mathrm{kg} \mathrm{m}^{-2}$ ), total AOD at $0.55 \mathrm{um}$ (c and d), total cloud cover (e and f; units: \%),

880 and relative humidity at $700 \mathrm{hPa}$ (g and h; units: \%) in MetUM-GOML1 (left panels) and MetUM-

881 GOML2 (right panels). The black dots highlight regions where the changes are statistically significant at the $90 \%$ confidence level based on a two-tailed Student's $t$-test. 
